\title{
ANÁLISIS CRÍTICO DE LA RETENCIÓN POLICIAL EN TORNO A LAS PRUEBAS DE DETECCIÓN ALCOHÓLICA DESDE UNA PERSPECTIVA CONSTITUCIONAL
}

VALENTÍN GUILLÉN PÉREZ

N.o 111, mayo-agosto 2021 
SUMARIO

1. PALABRAS PREVIAS: PRESENTACIÓN DE LA CUESTIÓN. 2. LA RETENCIÓN POLICIAL Y SUS LIMITACIONES EN EL DERECHO A LA LIBERTAD EN TORNO A LAS PRUEBAS DE ALCOHOLEMIA. 2.1. Antecedentes y su naturaleza jurídica. 2.2. Las retenciones policiales simples. 2.3. La retención policial consistente en trasladar a dependencias policiales. 3. INADMISIBILIDAD DEL TERTIUM GENUS EN EL ÁMBITO DE LA SEGURIDAD VIAL. 3.1. Falta de previsión legal. 3.2. Falta de medios de pruebas. 3.3. El papel que juega la aquiescencia del sometido para la admisibilidad del traslado. 3.4. El principio de proporcionalidad y menor aflictividad para terceros. 3.5. La existencia de un interés o exigencia pública que justifique el traslado. 4. LA ADMISIBILIDAD EN LA INVESTIGACIÓN EX. ART. 379.2. 5. A MODO DE CONCLUSIÓN. 6. BIBLIOGRAFÍA. 


\title{
ANÁLISIS CRÍTICO DE LA RETENCIÓN POLICIAL EN TORNO A LAS PRUEBAS DE DETECCIÓN ALCOHÓLICA DESDE UNA PERSPECTIVA CONSTITUCIONAL
}

\author{
VALENTÍN GUILLÉN PÉREZ
}

\section{PALABRAS PREVIAS: PRESENTACIÓN DE LA CUESTIÓN}

La libertad de todo ciudadano constituye un valor supremo de nuestro ordenamiento jurídico y un principio inspirador ${ }^{2}$ que conforma el derecho fundamental sancionado en el artículo 17 de nuestra Carta Magna, incardinado, a su vez, en el marco jurídico supranacional ${ }^{3}$. El debate factual, por consiguiente, lo hemos de centrar en dilucidar sobre la constitucionalidad o no de aquellas actuaciones policiales que afecten de algún modo u otro este derecho fundamental, en cuanto aquéllas pudieren precisar, en su caso, de una mayor dilación temporal para la realización de cuantas pesquisas fueran necesarias por parte de los agentes de la autoridad con el fin de alcanzar el fin legítimo perseguido; y entre las que pudiere hallarse el traslado del sujeto concernido a otro lugar distinto de donde se hubiera practicado el primer requerimiento, todo ello, y tal y como hemos explicado, con el único fin de materializar la precisa diligencia policial que ayude a esclarecer los hechos investigados.

1 Doctor en Abogacía y Práctica Jurídica (UCAM), Subinspector de la Policía Local de San Pedro del Pinatar (Murcia), Calle Alcalde José María Tárrega, S/N, C.P. 30740, San Pedro del Pinatar (Murcia). Email: pinatar2003@hotmail.com.

2 También en sumo detalle, DUTÚ I GURI, M.M. (2013), Los derechos fundamentales: Derecho a la liberad frente a las medidas cautelares penales, Barcelona, Bosch Editor, pp. 115-118.

3 Como destaca la Declaración Universal de los Derechos Humanos, de 10 de diciembre de 1948 (ONU), el Convenio Europeo para la Protección de los Derechos Humanos y Libertades fundamentales, de 1950 (Roma, 4 de diciembre), y el Pacto Internacional de Derechos Civiles y Políticos, de 19 de diciembre de 1966 (Nueva York), entre otros. 
Sin duda, la práctica de la prueba de alcoholemia conforma una restricción de la libertad de leve intensidad ${ }^{4}$. Asimismo, se ha de tener muy en cuenta que la duración para ejecutar esta prueba pericial es totalmente imprecisa y no podrá establecerse de antemano, puesto que variará en cada caso en función de las circunstancias concurrentes sobrevenidas.

No nos cabe la menor duda de que algún lector escéptico pueda considerar que dicho estudio, aparentemente, esté exento de dificultad —incluso de una forma instrumental—, habida cuenta de que en la sociedad actual existe un reconocimiento o justificación teleológica sobre dicho tema, y a propósito también de su regulación en el ordenamiento jurídico español. Sin embargo, creemos necesario puntualizar que estas diligencias no están exentas de problemas, en cuanto que, en ocasiones excepcionales, surgen casos concretos — debido a vicisitudes añadidas- que inexcusablemente exigen el traslado del conductor a las dependencias policiales donde se disponga del correspondiente etilómetro evidencial, sin que previamente se haya procedido a su detención.

La efectividad de su práctica, por ende, discurrirá por un terreno movedizo de difícil solución que garantice el mantenimiento del arduo equilibrio entre seguridad vial y libertad. Tanto es así, que incluso podría parecernos que ambos términos pudieran resultar antinómicos 5 , y su engranaje, por ello, irresoluble. La solución de esta dicotomía es de carácter heterogéneo en vista a las circunstancias de cada supuesto en concreto, que pasa por encontrar el correspondiente equilibrio entre el interés de la justicia, en su misión de perseguir los delitos contra la seguridad vial y, por otro lado, el respeto a aquellos conductores que se vieren afectados por la práctica de las actuaciones reseñadas.

Nos encontramos, por tanto, en un punto introspectivo con ocasión del debate público generado en torno a la legalidad del traslado de un sujeto a comisaría para la realización del control de alcoholemia, principalmente, porque dicha figura jurídica dentro del ámbito de la seguridad vial adolece de la correspondiente previsión normativa que satisfaga el rango de $l e y^{6}$. Tanto es así, que el estudio de este trabajo

4 También, con sumo detalle se expresa GARCÍA MORILLO, J. (1995), El derecho a la libertad personal, Valencia, Tirant lo Blanch, p. 22, cuando analiza en su obra, la privación, restricción o limitación de la liberad, esgrimiendo que la libertad personal alcanza su máxima intensidad cuando el origen se realiza por los agentes o los poderes públicos distintos del poder judicial.

5 A este respecto señala LOMBARDERO EXPOSITO, L.M. (2012), «Conflicto entre derechos fundamentales e investigación policial: el caso del cacheo», Revista de Estudios Jurídicos, 12, p. 1.

6 En el artículo científico de MARTÍ́N RÍOS, P. (2018), «El derecho a la libertad personal frente a la retención policial con fines de identificación», Revista Española de Derecho Constitucional, 12, p. 94, podemos extrapolar este aspecto de los traslados a efectos de realizar la diligencia de identificación con respecto a las pruebas de alcoholemia. De modo que antes de regularse dicha figura jurídica en la Ley Orgánica 1/1992, de 21 de febrero, sobre Protección de Seguridad Ciudadana (ahora derogada por la actual Ley Orgánica 4/2015) hubo mucha controversia entre la doctrina científica con respecto a estos traslados, por carecer de normativa que lo regulara. 
puede ayudar a dar pautas claras a las Fuerzas y Cuerpos de Seguridad en sus respectivas actuaciones.

La razón de este trabajo es llevar un minucioso estudio al respecto mediante la comparación de esta práctica policial con otras figuras jurídicas de calado similar, y que a diario son utilizadas en el ejercicio de sus funciones.

Nos estamos refiriendo, por ejemplo, al traslado de personas a dependencias policiales a los solos efectos de identificación policial ${ }^{7}$, así como también a los registros corporales externos ${ }^{8}$. Ahora bien, no hemos de obviar que además de éstas, existen también otras prácticas análogas como son las exploraciones radiológicas o las tomas de muestras biológicas ${ }^{9}$, entre otras.

Todas estas figuras indagatorias, por consiguiente, nos llevan consecuentemente a plantearnos la existencia de una situación intermedia entre la libertad y la detención ${ }^{10}$. Y precisamente, por ello, el debate generado en torno a esta figura o situación jurídica no constituye únicamente para nosotros un mero ejercicio de debate jurídico, sino que consideramos que este asunto es de suma importancia, ya que lleva consigo pragmáticas consecuencias entre las que, sin un ápice de duda, pudiere llegar a conculcarse, de algún modo, el derecho a la libertad de las personas.

\section{LA RETENCIÓN POLICIAL Y SU LIMITACIÓN EN EL DERECHO A LA LIBERTAD EN LAS PRUEBAS DE ALCOHOLEMIA}

\subsection{Antecedentes y su naturaleza jurídica}

En casi medio siglo de democracia en España, ha llegado a modificarse un sinfín de leyes con la intención de armonizar la práctica de la prueba de alcoholemia desde un plano jurídico-práctico. Todos estos cambios legislativos, a lo largo de estos años, han ido condicionando la praxis policial en atención al contexto y reclamo social sobre la persecución de conductas ilícitas relacionadas con la seguridad vial. Por primera

7 Referidas a los traslados a efectos de identificación.

8 Véase las siguientes sentencias del Tribunal Supremo; la STS norec. 1271/1994, de 23 de diciembre, [ECLI:ES:TS:1994:8883]; la STS no rec. 475/1994, de 23 de febrero, [ECLI:ES:TS:1994:1164], la STS 610/1994, de 30 de junio, [ECLI:ES:TS:2010:3676] y la STS 1347/2011, de 30 de noviembre, [ECLI:ES:TS:2011:8999] entre otras. Se hace constar que el listado de repertorio jurisprudencial utilizado a lo largo de la presente investigación, corresponde al Centro de Documentación Judicial (CENDOJ), del Consejo General del Poder Judicial. Se han seguido las disposiciones que han tenido lugar en el identificador europeo de jurisprudencia (ECLI). Disponible en: http://www.poderjudicial.es/ search/indexAN.jsp [consulta: 26 febrero 2020].

9 SOTO RODRÍGUEZ, M.L. (2014), «Las intervenciones corporales y vulneración de derechos fundamentales, Diario la Ley, 8392, p. 14.

10 DUART ALBIOL, J.J. (2014), Inspecciones, registros e intervenciones corporales en el proceso penal, Barcelona, Bosch, p. 234.

(C) UNED. Revista de Derecho Politico

N. ${ }^{\circ} 111$, mayo-agosto 2021, págs. 191-224 
vez en España, se dispuso la Orden de 29 de julio de $1981^{11}$ que otorgaba la facultad a los agentes encargados de la vigilancia del tráfico para proceder a la retención del conductor (en el lugar de los hechos o en dependencias policiales), que diere positivo en la prueba pericial practicada, hasta que hubieren desaparecido los efectos o causas de la intoxicación etílica ${ }^{12}$. Sorprende además, que dicha regulación se incluyera en una disposición de carácter administrativa como veremos a continuación.

Por ende, la locución «retención» ${ }^{13}$ aparece en una norma de tráfico para referirse a una medida coactiva que afecta al derecho a la libertad del conductor sometido a las pruebas de detección alcohólica. Sin embargo, nos parece del todo llamativo ${ }^{14}$, que dicho término no haya sido determinado por el legislador, en referencia al transcurso del tiempo que pudiera durar la preceptiva prueba, sino más bien, hace mención al intervalo que el sujeto concernido necesite desde el inicio de las pruebas hasta que desaparezcan las causas que originaron la inmovilización del vehículo.

No obstante, a pesar de esta parquedad jurídica incorporada en el citado artículo, el Tribunal Constitucional se pronunció en el año $1985^{15}$ y $1988^{16}$ sobre su legitimidad, incluyendo el supuesto de la presencia física del conductor en las dependencias policiales donde se realizarán las pruebas. El alto Tribunal consideró que dicha medida coactiva no suponía una privación de libertad, y, por lo tanto, no adolecía de las exigidas garantías que refiere el artículo 17.3 del texto constitucional. De modo que supone «para el afectado, un sometimiento, no ilegítimo desde la perspectiva constitucional, a las normas de policía» ${ }^{17}$. Pese a todo, esta figura jurídica cuyos efectos conculca el derecho a la libertad (como veremos en los siguientes apartados), acabaría convirtiéndose en una situación distinta a la detención ${ }^{18}$.

11 Orden de 29 de julio de 1981, sobre investigación del grado de impregnación alcohólica de los usuarios de las vías públicas, publicado en el B.O.E. n¹86, de 05 de agosto de 1981.

12 Ex. art. 5 de la citada Orden.

13 En la monografía del tratadista MARTíN RÍOS, P. (2018), menciona la «retención simple», al analizar la Orden de 29 de junio de 1981 anteriormente reseñada («El derecho a...», op. cit., p. 95).

14 Véase en este sentido, BANACLOCHE PALAO, J. (1996), La libertad personal y sus limitaciones, Madrid, MacGraw-Hill, pp. 234 y s.

15 STC 107/1985, de 7 de octubre.

16 STC 22/1988, de 18 de febrero. Establece en su FJ1 ${ }^{\circ}$ que «no es posible equiparar la privación de libertad a que se refiere el art. 17 CE con la presencia física de una persona en las dependencias policiales para la práctica de una diligencia por el tiempo estrictamente necesario para llevarla a cabo».

$17 \mathrm{FJ}^{\circ}$ de la STC 107/1985, de 7 de octubre.

18 FREIXES SANJUAN, T. (1993), «Reflexiones sobre la interpretación constitucional del derecho a la libertad personal», Revista Vasca de Administración Pública, 35, p. 95. No es menos cierto que existe discrepancia por el mismo TC, concretamente en la sentencia 98/1986, de 10 de julio. En su FJ4º, arguye, que no puede encontrarse zonas intermedias entre la libertad y la detención, no obstante coincidimos con el autor ASENCIO MELLADO, J.M. (1994), «La detención a los solos efectos de identificación personal prevista en el artículo 20 del proyecto de la Ley Orgánica sobre Protección de la Seguridad Ciudadana», Revista del Instituto Bartolomé de las Casas. Derechos y Libertades, 2, p. 26, cuando expresa que dicha sentencia «ha de situase en su contexto preciso y en relación con el específico tema que se sometió a la consideración del Tribunal». A nuestro juicio, es posible que haya tenido consecuencias para la promulgación de sucesoras leyes con respecto a la retención policial desde ese año, sin 
A la luz de lo anterior, grandes tratadistas de la comunidad científica ${ }^{19}$ han dilucidado sobre aspectos destacados en las citadas resoluciones, causa suficiente para no ser tautológicos con respecto a la profundidad de su análisis. Incluso en la actualidad, la repercusión con respecto a la figura de la retención policial consistente en los traslados a efectos de las pruebas de alcoholemia tiene escasa trascendencia ${ }^{20}$, principalmente, porque debe ser objeto de algunos matices ${ }^{21}$ con respecto a la nueva legislación como estudiaremos en los apartados ut infra. Una de las causas principales se debe a la publicación de la STC 341/1993, de 18 de noviembre, mediante la cual se cuestiona la inconstitucionalidad del artículo 20.2 de la Ley Orgánica de Protección de Seguridad Ciudadana (en lo sucesivo LOPSC) de 1992. En ella se disertó sobre los traslados a dependencias policiales a efectos de practicar una identificación. De modo que existe un precedente significativo a partir de ese año para su debido análisis.

En efecto, la posición con respecto a esta figura o situación jurídica cambió radicalmente ${ }^{22}$ a partir de aquella sentencia. El Tribunal resolvió el recurso y la cuestión de inconstitucionalidad planteada ex. art. 20.2 de la LOPSC de 1992, en cuyos argumentos llegó a aceptar una modalidad de privación de libertad (retención) consistente

embargo, puede generar dudas en su interpretación para aquellas diligencias policiales que supongan un efecto cuantitativamente reducido por ser medidas provisionalísimas en el tiempo, como sucede en la práctica del cacheo, las pruebas de alcoholemia, o, incluso las identificaciones policiales.

19 Sobre la cuestión, ampliamente; CASAL HERNÁNDEZ, J.M. (1998), Derecho a la libertad personal y diligencias policiales de identificación, Madrid, Centro de estudios políticos y constitucionales, $\mathrm{p}$. 266; BANACLOCHE PALAO, J. (1996), «La libertad personal...», op. cit., pp. 234-242. Dicho tratadista, establece que según la interpretación de la STC 28/1988, de 18 de febrero, no requiere ni siquiera que la prueba de alcoholemia se encuentre regulada en una norma con rango de ley, por la consideración de un caso más de sujeción general en el administrado (en este caso al conductor del vehículo), por lo tanto, no existe ninguna vulneración en el derecho fundamental; GARCÍA MORILLO, J. (1995), «El derecho a...», op. cit., pp. 211-213; MARTÍN RÍOS, P. (2018), «El derecho a...», op. cit., pp. 96-97, GONZÁLEZ MONTES, F. (2007), «Especialidades procesales en los juicios penales por hechos de tráfico», en MORILLAS CUEVA, L. (coord.), Delincuencia en materia de tráfico y seguridad vial, Madrid, Dykinson, pp. 606 y s.; y DUTÚ I GURI, M.M. (2013), «Los derechos fundamentales...», op. cit., pp. 131-135, entre otros.

20 Véase la referencia de VILLAVERDE MENÉNDEZ, I., y CUBA VILA, J. (2009), «Alcoholemias, tráfico y otras tribulaciones constitucionales. Punto y aparte en la ley seca de la sanción administrativa», Revista de Documentación Administrativa, 284-285, p. 181.

21 En el mismo sentido, GONZÁLEZ MONTES, F. (2007), «Especialidades procesales en...», op. cit., p. 606, y BANACLOCHE PALAO, J. (1996), « La libertad personal...», op. cit., p. 242, duda sobre la constitucionalidad si llegados al caso, se aprobara una ley de tráfico que incluyera esta figura jurídica.

22 En el mismo sentido, MÁLAGA DIÉGUEZ, F. (2001), «Detención y retención», Revista de derecho procesal, 1, p. 163. Incluso JAREÑO LEAL, A. (2019), «La privación de libertad a efectos de identificación en la Ley de Seguridad Ciudadana: sus requisitos y la distinción entre delitos e infracciones administrativas de desobediencia y de resistencia en caso de negativa a identificarse, Cuadernos de Política Criminal, 128, Época II, p. 9, afirma, que se aceptó dicha figura en el mismo ordenamiento jurídico. Además de los dos autores citados, GARCÍA MORILLO, J. (1995), «El derecho a...», op. cit., p. 21, asevera que los supuestos de privación de libertad, no cobran un mayor interés, por la resolución del recurso de inconstitucionalidad, sino más bien desde la aprobación de la LOPSC de 1992. Dicho tratadista reconoce que genera un debate jurídico, social e incluso político.

N. ${ }^{\circ} 111$, mayo-agosto 2021, págs. 191-224 
en acompañar ${ }^{23}$ a las dependencias policiales más próximas en las que pueda efectuarse dicha identificación ${ }^{24}$.

Además, señala el TC que será de aplicación, al menos, la garantía constitucional incluida ex. art. 17.2 de la CE, la cual dispone que «no podrá durar más del tiempo estrictamente necesario para la realización de las averiguaciones tendentes al esclarecimiento de los hechos» ${ }^{25}$. Así como ex. art. 17.3 de la CE que versa sobre la explicación de los motivos y las causas que deben disponer los cuerpos policiales españoles para practicar la detención ${ }^{26}$.

Por lo tanto, a partir de esta resolución hay que señalar que la «conflictiva figura de la retención» ${ }^{27}$ origina disertaciones discrepantes en el campo de la comunidad científica. Sin embargo, somos de la opinión que la citada figura posibilita la admisibilidad de un tertium genus entre la libertad y la detención, de modo que da sentido al carácter de la Ley Orgánica ex. art. 20.2, a propósito de las diligencias de identificación.

Valga a título meramente ilustrativo, que la cuestionada resolución judicial continúa la línea que dispuso el Tribunal Constitucional en la sentencia 178/1985, al aludir que «el artículo 17.1 CE no concibe la libertad individual como un derecho absoluto y no desprovisto de restricciones ${ }^{28}$. A pesar de todo ello, el legislador sigue sin incluir la locución de la retención policial ${ }^{29}$ en la nueva LOPSC, para los casos de traslados a efectos de identificación —esta vez reconocidos en el artículo 16.2-, a pesar de ser admitido, incluso, por la Sesión Plenaria del año 2015 durante el debate del Anteproyecto de dicha norma ${ }^{30}$.

23 MARTÍN RÍOS, P. (2018), «El derecho a...», op. cit., p. 96, critica en su obra la expresión «acompañar» como un eufemismo legal al que no tiene regulación en la CE. Sin embargo, CASAL HERNÁNDEZ, J.M. (1998), «Derecho a la...», op. cit., p. 261, utiliza la locución de «conducido» por la policía para hacer mención ante la privación de libertad del citado artículo 20.2 (LOPSC 1/1992), y por último GONZÁLEZ MONTES, F. (2007), «Especialidades procesales en...», op. cit., p. 606, añade el término «conducción» para referirse a la retención policial sobre dichos aspectos legales.

24 JAREÑO LEAL, A. (2019), «La privación de...», op. cit., p. 29. Además, afirma nuestro autor que se trata de una «obligación legal» del ciudadano a cumplir las órdenes de los agentes, incluso, mediante la privación de libertad del sujeto concernido a las diligencias de identificación. (Todo ello queda desarrollado en el FJ3º de la STC 341/1993, de 18 de noviembre).

25 STC 341/1993, de 18 de noviembre, FJ5 ${ }^{\circ}$.

${ }^{26}$ Idem. El FJ6 $6^{\circ}$ lo expresa de la siguiente forma: «que el requerido a acompañar a la fuerza pública debe ser informado, de modo inmediato y comprensible, de las razones de tal requerimiento es cosa que apenas requiere ser argumentada, aunque la Ley (que exige consten en el Libro-Registro los motivos de las diligencias practicadas) nada dice, de modo expreso, sobre esta información».

27 GONZÁLEZ MONTES, F. (2007), «Especialidades procesales en...», op. cit., p. 606.

$28 \mathrm{FJ}^{\circ}$ de la STC 178/1985, de 19 de diciembre, lo que ahora conocemos como localización permanente.

29 Término que utiliza MATÍA PORTILLA, F.J. (1997), El derecho fundamental a la inviolabilidad del domicilio, Madrid, McGraw-Hill, p. 244, para referirse a la figura que se llevó a colación en la señalada ya, STC 341/1993.

30 Intervención del Ministro del Interior en el debate político recogido en el Diario de Sesiones del Congreso de los Diputados (2015), 269, p.66. Establece en sus argumentaciones que, «se regulan 
A pesar de ello, el desarrollo del artículo 16 de la LOPSC ha sido más prolijo y garantista ${ }^{31}$ con respecto al artículo 20 de la antigua ley, incluyendo cuantiosos aspectos importantes como son el expreso cumplimiento del principio de proporcionalidad; la interposición de una duración máxima de permanencia en comisaría de seis horas; el deber expreso de informar sobre los motivos y causas de su traslado, así como la prohibición de realizar identificaciones en razón del sexo, raza, religión, etc. En este sentido, resulta interesante realizar una reflexión sobre esta situación o figura restrictiva de la libertad que planteó el alto Tribunal, porque se asemeja ${ }^{32}$ en el desarrollo de la preceptiva prueba de alcoholemia por parte de los agentes de la autoridad. Por consiguiente, nos obliga a adentrarnos en el análisis de la naturaleza jurídica de la retención.

\subsection{Las retenciones policiales simples ${ }^{33}$}

Las retenciones policiales que, por su leve intensidad, revistan un carácter coactivo provisionalísimo o momentáneo sobre el sujeto concernido, de modo que, se prolonguen únicamente en el tiempo cuando sea indispensable para llevar a cabo el cometido de determinadas funciones policiales ${ }^{34}$, - como son, entre otras, las identificaciones,

por primera vez en esta ley cosas que hasta ahora no estaban reguladas (...) la retención, esa figura entre la detención y la libertad». También fue reconocida por el Dictamen del Consejo de Estado 557/2014, sobre el Anteproyecto de la LOPSC, con fecha de 26 de junio del 2014, cuando alude ex. art. 16.2 de la LOPSC, para referirse a la «restricción de libertad» en las figuras de indagación policial: como el cacheo o la identificación (art. 16.1 de la actual LOPSC), disponible en: http://www.consejo-estado.es/transparencia/view.php?id=248 (consultado el 28/04/2020).

31 En términos parecidos, JAREÑO LEAL, A. (2019), «La privación de...», op. cit., pp. 11 y s., añadiendo incluso, que la actual ley lleva consigo una justificación teleológica en los siguientes términos «es indudable que la ley ha sido socialmente aceptada por lo que se refiere a las medidas que aquí se están analizando» (p.10).

32 Insiste en ello, VIDAL PRADO, C. (1997), «Algunos límites del derecho a la libertad personal: Controles de alcoholemia, legislación y jurisprudencia», Revista de la Facultad de Derecho y Ciencias Políticas, 98, p. 141.

33 Coincidimos con la denominación de «la retención policial simple» en los casos que para su práctica constituya un carácter leve, como destaca MARTÍN RÍOS, P. (2018), «El derecho a...», op. cit., p. 93, al apuntar que la diligencia de identificación del artículo 16.1 de la LOPSC 4/2015 se consideran «retenciones leves» o «retenciones puras» (p. 98), cuando conlleven una identificación in situ que no suponga trasladar al sometido a comisaría. Sin embargo, VIDAL PRADO, C. (1997), cuando realiza el estudio de esta figura jurídica con respecto a las pruebas de alcoholemia, utiliza la locución de «zona de sombra» para mencionarla («Algunos límites del...», op. cit., p. 120), o incluso FREIXES SANJUAN, T. (1993), «Reflexiones sobre la...», op. cit., p. 95, en cuyo caso lo describe como una «zona de penumbra».

34 MÁlAGA DiÉGUEZ, F. (2001), «Detención y retención», op. cit., pp. 161 y s. Además, GIMENO SENDRA, V. (1988), Constitución y Proceso, Madrid, Tecnos, p. 63, establece, que las pruebas de alcoholemia afectan a la libertad de movimientos, por el necesario tiempo desempeñado a fin de determinar el grado de alcohol en la sangre.

(C) UNED. Revista de Derecho Politico

N. ${ }^{\circ} 111$, mayo-agosto 2021, págs. 191-224 
la práctica del cacheo ${ }^{35}$, así como las pruebas de alcoholemia (objeto de estudio)—y no supongan para el afectado la conculcación de su derecho a la libertad, ni a su derecho a circular libremente por territorio español ${ }^{36}$. En este sentido, también se ha pronunciado a tal respecto tanto la doctrina científica ${ }^{37}$ como la jurisprudencial $^{38}$. En los argumentos esgrimidos, se reconoce la legitimidad sobre la verificación de las pruebas de alcoholemia, habida cuenta de que al no constituir una detención en sentido estricto, no cabe la implementación oportuna de las garantías constitucionales previstas para los supuestos de privación de libertad llevados a cabo en los traslados a efectos de identificación.

Pues bien, en el primer expositivo de la STC 341/1993, refleja que: «es cierto que el Tribunal Constitucional ha admitido que una privación de libertad momentánea (para la práctica de la llamada prueba de alcoholemia) no constituye detención (SSTC 103/1985 y 107/1985), pero aquí estamos ante un supuesto diferente, pues tal prueba tiene su origen en una relación de supremacía especial regulada por normas de policía de tráfico, lo que no concurre en el supuesto del impugnado art. 20.2».

Y precisamente en este punto conviene traer a colación la consideración de que estas situaciones de sujeción no pueden reputarse como una detención y, por tanto, exigir las correspondientes garantías que sanciona ex. art. 17 de nuestra Carta Magna. En este sentido coincidimos con MÁLAGA MIÉGUEZ, cuando arguye que «además de impracticable resultaría a todas luces desproporcionado» ${ }^{39}$ considerar una detención en algunas actividades policiales como la notificación al conductor de un vehículo de una denuncia o una citación judicial ${ }^{40}$; obligar a un peatón permanecer en un lugar determinado para asegurar la celebración de un evento; o

35 Regulado actualmente en el artículo 20 de la LOPSC 4/2015 con la locución «registro corporal externo». La jurisprudencia ha sido unánime en aseverar que la afectación al cacheo, es cuantitativamente reducido. Por todas la STS n ${ }^{\circ}$ rec. 3054/1995, de 07 de julio, [ECLI:ES:TS:1995:3997]. Coincidimos además con FERNÁNDEZ-GALLARDO FERNÁNDEZ-GALLARDO, J.A. (2015), Cuestiones actuales del proceso penal, Barcelona, Experiencia, p.142, al analizar la doctrina jurisprudencial en el ámbito de las retenciones sobre los cacheos, concluyendo que no puede ser extendida esta práctica a las previsiones que exige la LECR, como si sucede con la detención policial.

36 Insiste en ello, DUART ALBIOL, J.J. (2014), «Inspecciones, registros e...», op. cit., p. 240, añadiendo incluso las exploraciones radiológicas que realizan los agentes de la autoridad.

37 En sumo detalle; BANACLOCHE PALAO, J. (1996), «La libertad personal...», op. cit., p. 241; GARCÍA MORILLO, J. (1995), «El derecho a...», op. cit., p. 212; MÁLAGA DIÉGUEZ, F. (2001), «Detención y retención», op. cit., p. 151 y DUTÚ I GURI, M.M. (2013), «Los derechos fundamentales...», op. cit., pp. 136-140.

38 Por todos, la ATS 33/2007, 11 de enero, [ECLI:ES:TS:2007:521A], en cuyos argumentos arguye una abultada jurisprudencia al respecto $\left(\mathrm{FJ} 1^{\circ}\right)$. Incluso se atreve a expresar que «las meras retenciones o provisionalísimas restricciones de libertad que comportan de modo inevitable determinadas diligencias no dirigidas contra la libertad ambulatoria (pruebas de alcoholemia, identificaciones, o cacheos)». De igual modo, y en los mismos términos refiere el FJ1º de la STS 976/1999, de 17 de junio, [ECLI:ES:TS:2011:8999].

39 MÁlAGA DIÉGUEZ, F. (2001), «Detención y retención», op. cit., p. 154.

40 DUTÚ I GURI, M.M. (2013), «Los derechos fundamentales...», op. cit., p. 137. 
incluso permanecer un breve tiempo en el detector de metales antes de embarcar en el aeropuerto.

Dicho lo cual, y aun considerando que el corto lapso de tiempo necesario para realizar la prueba de alcoholemia está legitimado, se podría incurrir en la conculcación del derecho a la libertad si las comprobaciones de los funcionarios públicos se extralimitasen o se prolongaren por un tiempo injustificado. En otras palabras, suscribimos lo que arguye el tratadista BANACLOCHE PALAO en su reconocida obra, al aseverar que «si la retención de una persona con objeto de comprobar su grado de alcoholemia se practica sin respetar alguno de los requisitos que determinan su validez, entonces tal retención será ilegal, y al margen de las responsabilidades penales y disciplinarias que puedan originar para su autor, justificará la oposición del afectado a la práctica de la misma» ${ }^{41}$.

Y conforme a la legalidad instrumental, coincidimos también con DUART $\mathrm{ALBIOL}^{42}$ al reseñar que, la urgencia de ciertas prácticas, exige una actuación de los agentes lo suficientemente rápido para que no se frustre el resultado de la investigación. Concretamente con la determinación de la prueba de alcoholemia por aire inspirado o incluso la verificación de la presencia de drogas tóxicas.

\subsection{La retención policial consistente en trasladar a dependencias policiales}

Otra de las figuras o situaciones jurídicas objeto de estudio del presente trabajo, es la concerniente a las actuaciones policiales que originen las citadas retenciones, pero conteniendo un plus de intensidad superior a la modalidad anterior por superar el umbral temporal de lo permitido, de forma que suponga para el sujeto concernido una situación «que va más allá que la mera inmovilización de la persona (...) y por ello ha de ser considerada como una modalidad de privación de libertad» ${ }^{43}$. En rigor, esta argumentación jurídica pertenece a la conocida STC 341/1993, en cuyos argumentos se dilucida sobre la constitucionalidad del traslado a dependencias policiales a fin de realizar una diligencia de identificación. Se configuran estos términos, como un punto de partida en la reflexión de nuestro análisis con respecto a las pruebas de alcoholemia.

Como ejemplo de ello, en cuanto a la citada identificación policial en vía pública sobre un sujeto indocumentado, cuando los agentes de la autoridad agotasen los medios a su alcance, tendrán la posibilidad de trasladarlo a comisaría a fin de practicar las oportunas comprobaciones. De igual modo, con respecto al «registro corporal

41 BANACLOCHE PALAO, J. (1996), «La libertad personal...», op. cit., p. 249.

42 DUART ALBIOL, J.J. (2014), «Inspecciones, registros e...», op. cit., pp. 343 y s.

43 FJ4 $4^{\circ}$ de la STC 341/1993, de 18 de noviembre. El FJ1 ${ }^{\circ}$ de la SAP de Alicante 316/2003, de 11 de junio, [ECLI:ES:APA:2003:2419], se hace eco de la «retención», para dilucidar un supuesto consistente en el traslado a dependencias policiales a fin de realizar la prueba de alcoholemia. 
externo» ${ }^{44}$ conocido vulgarmente como la práctica del cacheo ${ }^{45}$, existen situaciones en las que los funcionarios policiales precisen de un lugar idóneo donde trasladar a la persona, en aras de preservar su intimidad personal o corporal — según el grado de intensidad, y si afecta o no al pudor o recato del sujetoun sometimiento que consista en dejar a la vista aquellas partes del cuerpo que normalmente estén cubiertas por ropa — más conocido como desnudo parcial ${ }^{46}$ - Como observamos en este supuesto, el nivel de afectación a la libertad es muy superior a la simple palpación o comprobación que se realiza en la vía pública o in situ, con el fin de perseguir, indagar y prevenir hechos constitutivos de delitos. Es necesario excluir con respecto a la figura anterior, aquellas actuaciones policiales que, por su singularidad, puedan conducir a meras detenciones gubernativas o administrativas ${ }^{47}$ : la detención de extranjeros para su expulsión del territorio nacional o la incoación del correspondiente expediente administrativo de expulsión o devolución; la detención por el estado de alarma o sitio, y la detención de portadores de infecciones contagiosas, entre otros. En este sentido puntualiza la tratadista MÁLAGA DIÉGUEZ que «a menos que la propia persona solicite ser conducida a un lugar reservado para ser registrada, su traslado a dependencias policiales sólo será posible si previamente se practica su detención» ${ }^{48}$.

Por tanto, conviene traer a colación el problema existente cuando la citada inmovilización provisionalísima en el tiempo, pueda prolongarse como consecuencia de alguna vicisitud extemporánea cada vez que, en el ejercicio de las funciones propias de los agentes policiales, se vean compelidos a trasladar al conductor de un vehículo a comisaría policial para verificar la tasa de alcohol con un etilómetro homologado.

44 Por primera vez en España, y en materia de seguridad ciudadana, se regula bajo la rúbrica ex. art. 20 de la LOPSC el «registro corporal externo», comúnmente conocido como la diligencia del cacheo.

45 Como destacaba el Ministro del Interior Jorge Fernández Díaz, en el Diario de sesiones del Congreso de los Diputados no 230, del 16 de octubre de 2014, p. 25. Así como BILBAO UBILLOS, J.M., «La llamada ley mordaza: Ley Orgánica 4/2015 de Protección de la Seguridad Ciudadana», UNED-Teoría y Realidad Constitucional, 36, 2015, p. 234.

46 Coinciden en aludir dicho término en la figura del artículo 20.2.b de la actual LOPSC 4/2015; el Consell de Garanties Estatutàries de Catalunya, Dictamen 7/2015, de 4 de junio, sobre la Ley orgánica 4/2015, de 30 de marzo, de protección de seguridad ciudadana (2015), Consejo de Garantías Estatutarias de la Generalidad de Cataluña, p. 43, y GUILLÉN ÁLVAREZ, I. (2015), «Estudio y análisis jurídico de la nueva Ley Orgánica 4/2015, de protección de la seguridad ciudadana», Diario la Ley, 8633, p. 13. Así mismo BILBAO UBILlOS, J.M. (2015), op. cit., p. 235, y MONTERO RIVAS J. (2016), Seguridad ciudadana y derechos fundamentales: Luces y sombras de la Ley Orgánica 4/2015, Trabajo fin de Grado inédito, en GUERRERO COLMENARES, M. (dir.), Universidad del País Vasco, p. 37, esgrimen que esta acción puede convertirse, incluso, en un desnudo parcial o total.

47 GINER ALEGRÍA, C.A. (2014), Las medidas cautelares penales personales en el proceso penal español y su vinculación con los Derechos Fundamentales (especial referencia a las recomendaciones internacionales en materia de Derechos Humanos), Nicolás Guardiola, J.J. (dir.), Tesis doctoral, Facultad de Ciencias Jurídicas y de la Empresa de la Universidad Católica de Murcia, p. 203, reseña la locución «detención administrativa» para referirse a los supuestos que se mencionan en el texto principal.

${ }_{48}$ MÁlAGA DIÉGUEZ, F. (2001), «Detención y retención», op. cit., pp. 163 y s. 
En otras palabras, desaparecería «una esencial característica como es el carácter provisionalísimo» ${ }^{49}$ al practicar dicha prueba policial.

La casuística es de lo más variopinta como podrán comprobar en las siguientes líneas. Y que mejor modo de ilustrar la problemática del asunto con hechos fácticos dilucidados por parte de la jurisprudencia. Por ejemplo, imaginemos que el etilómetro evidencial se avería nada más iniciar la verificación del resultado en su primera prueba $^{50}$; o bien el etilómetro se queda sin batería cuando someten al conductor de un vehículo a la segunda de las pruebas legalmente establecidas ${ }^{51}$; o que la policía de una localidad carece de etilómetro evidencial como dotación ${ }^{52}$; o bien el hecho fáctico de disponer únicamente de un etilómetro digital de muestreo (no autorizado), y por dicho motivo, deben trasladar a sus dependencias policiales para realizar las oportunas pruebas con el etilómetro evidencial ${ }^{53}$. O bien, cuando agentes de la policía nacional requieren la presencia de la policía local (dotados éstos últimos de etilómetro) a fin de realizar las pruebas legalmente establecidas, sin que se haya provisto de etilómetro en el propio vehículo policial ${ }^{54}$. O el caso del conductor que voluntariamente accede a ser trasladado para la realización de la prueba pericial, y en mitad del trayecto cambia de parecer manifestando a los agentes que depongan el traslado a comisaría ${ }^{55}$. O también el supuesto de trasladar al conductor de un vehículo a dependencias policiales para realizar la prueba con un etilómetro diferente, en vista de que el sujeto fue inca-

49 Ibidem, pp. 161 y s.

50 FJ $4^{\circ}$ de la SAP de Córdoba 38/2000, de 12 de mayo, [ECLI:ES:APCO:2000:764].

51 FJ $2^{\circ}$ de la SAP de Palmas de Gran Canaria 217/2017, de 13 de julio, [ECLI:ES:APGC:2017:1710].

52 FJ1ํ de la SAP de Almería 26/2001, de 29 de enero, [ECLI:ES:APAL:2001:96] y FJ4º SAP de Badajoz 68/2004, de 30 de marzo, [ECLI:ES:APBA:2004:273].

53 SAP de Palma de Mallorca 84/2008, 05 de mayo, [ECLI:ES:APIB:2008:253]. En el presente supuesto de hecho es frecuente, aunque cada vez en menos porcentaje, que unidades de Policía Local no hayan sido dotados por la Administración de los correspondientes etilómetros evidenciales portátiles (téngase en cuenta lo establecido en la Orden ITC/3707/2006, de 22 de noviembre, por la que se regula el control metrológico del Estado de los instrumentos destinados a medir la concentración de alcohol en el aire espirado), dado que el etilómetro de muestreo no es válido como prueba de cargo para destruir la presunción de inocencia. Además la SAP de Huelva 355/2015, de 20 de octubre, [ECLI:ES:APH:2015:958], reconoce que la prueba de alcoholemia realizada con un etilómetro de muestreo «no constituye un medio idóneo para valorar los resultados» $\left(\mathrm{FJ}^{\circ}{ }^{\circ}\right.$. Al respecto, debemos aclarar la previsión del Real Decreto 1428/2003, de 21 de noviembre, por el que se aprueba el Reglamento General de Circulación para aplicación y desarrollo del texto articulado de la Ley sobre Tráfico, Circulación de Vehículos a Motor y Seguridad Vial, aprobado por el Real Decreto Legislativo 339/1990, de 2 de marzo (en adelante RGC), que del tenor literal de su artículo 22.1 establece que «las pruebas para detectar la posible intoxicación por alcohol se practicarán por los agentes encargados de la vigilancia de tráfico y consistirán, normalmente, en la verificación del aire espirado mediante etilómetros que, oficialmente autorizados, determinarán de forma cuantitativa el grado de impregnación alcohólica de los interesados», es decir, y como anteriormente se indicaba, no basta con una prueba llevada a cabo mediante etilómetro de muestreo, sino aquellos aparatos que por sus propias características estén homologados para llevarlas a cabo.

54 FJ $3^{\circ}$ de la SAP de Madrid 1467/2012, de 14 de noviembre, [ECLI:ES:APM:2012:18495].

$55 \mathrm{FJ}^{\circ}{ }^{\circ}$ de la SAP de Madrid 1182/2011, de 12 de diciembre, [ECLI:ES:APM:2011:18114].

(C) UNED. Revista de Derecho Politico

N. o 111, mayo-agosto 2021, págs. 191-224 
paz de insuflar correctamente con el etilómetro que había sido utilizado por los agentes en el lugar de los hechos ${ }^{56}$; o el traslado a dependencias policiales para la toma de muestra de saliva con el instrumento policial, a fin de realizar un test de droga ${ }^{57}$.

A pesar de que puedan producirse todas estas circunstancias al ejecutar la citada prueba pericial, el legislador no ha previsto explícitamente una regulación espacio-temporal en la norma, habida cuenta de que su realización contiene «una falta de certeza respecto de la exacta duración ${ }^{58}$, es decir, que el desarrollo de la misma precisa de un tiempo indeterminado que variará según las circunstancias de cada caso. Sorprende que respecto a las pruebas para detectar la posible intoxicación por alcohol, tanto la Ley de Seguridad Vial ${ }^{59}$ como el $\mathrm{RGC}^{60}$ que la desarrolla, no hayan hecho mención alguna a la durabilidad para la efectiva realización de las pruebas, como tampoco a su emplazamiento ${ }^{61}$. Únicamente redacta el legislador ex. art. 23.2 del RGC, que el espacio temporal entre la primera y la segunda prueba, transcurra, al menos, diez minutos de duración. Podemos apuntar, incluso, que las pruebas para detectar la presencia de drogas tóxicas, estupefacciones y sustancias psicotrópicas a pesar de su desarrollo en la $\mathrm{LECR}^{62}$, tampoco haya tenido a bien el legislador mencionar sobre la durabilidad de las mismas.

En cualquier caso, tanto la Ley Orgánica 2/1986, de 13 de marzo, de Fuerzas y Cuerpos de Seguridad ${ }^{63}$ como en otras normas especiales $^{64}$, se determinó —en términos generales-, la necesidad de aplicar una menor aflictividad en las personas con respecto a su tratamiento policial. Sobre el particular, deducimos, que las pruebas de detección alcohólica mediante aire espirado, los agentes precisarán del tiempo estrictamente necesario para llevarlas a cabo, porque llegados al punto de una extralimita-

56 FJ2 $^{\circ}$ de la SAP de Sevilla 635/2014, de 27 de noviembre, [ECLI:ES:APSE:2014:3671].

57 Sobre dicha cuestión dilucida la SAP de Barcelona 910/2016, de 15 de noviembre, [ECLI:ES:APB:2016:11709].

58 CASAL HERNÁNDEZ, J.M. (1998), «Derecho a la...», op. cit., p. 262.

59 Real Decreto Legislativo 6/2015, de 30 de octubre, por el que se aprueba el Texto Refundido de la Ley sobre Tráfico, Circulación de Vehículos a Motor y Seguridad Vial.

60 Comprendido entre el artículo 20 al 26 inclusive.

${ }_{61}$ Así lo expresa el FJ3 ${ }^{\circ}$ de la SAP de Barcelona 910/2016, de 15 de noviembre, [ECLI:ES:APB:2016:11709]. En este caso, habla de las pruebas de drogas en el ámbito de la seguridad vial.

${ }^{62}$ Actualmente, la prueba consistente en la exposición del test indiciario salival, se rige en el artículo 796.1.7. de la LECR. La última modificación al respecto se estableció por la Ley Orgánica 5/2010, de 22 de junio, por la que se modifica la Ley Orgánica 10/1995, de 23 de noviembre, del Código Penal.

${ }_{63}$ El artículo 5.2.C establece, que las FCS deberán de actuar en el ejercicio de sus funciones sin demora, en atención al principio de proporcionalidad, oportunidad y congruencia cuando refiere para la utilización de los medios que tengan a su alcance.

64 La LOPSC 4/2015 reza en el artículo 16.2, sobre el traslado a dependencias policiales a efectos de realizar la identificación. La misma expresa que tendrá lugar por «el tiempo estrictamente necesario, que en ningún caso podrá superar las seis horas». También menciona el artículo 21 de la citada ley, otras diligencias que incumbe en las restricciones deambulatorias recaídas en materia de seguridad ciudadana, como es el caso del «cierre o desalojo de locales o establecimiento, la prohibición del paso, la evacuación de inmuebles o espacios públicos debidamente acotados». Véase también, el artículo 520 de la LECR, en referencia a la detención preventiva llevada a cabo por las FCS. 
ción, incurrirían entonces en un posible ilícito penal o administrativo (expediente disciplinario), según el caso concreto o la intensidad inferida al respecto.

De tal modo, podemos aseverar que las pruebas de alcoholemia pueden prolongarse en el tiempo, incluso en más de media hora según las vicisitudes del caso concreto $^{65}$. Como por ejemplo estar sumido dentro de los programas de los controles preventivos de alcoholemia ordenados por la autoridad competente; o bien, la resolución de un accidente de circulación que incluso implique la notificación de la comisión de una infracción, a las normas contenidas del RGC.

Dicho lo cual, y sea como fuere, lo cierto es que hay que tener en cuenta el proceso que los agentes de la autoridad llevan a cabo para la comprobación de dichas pesquisas, visto que conllevan una complejidad añadida: solicitar al conductor que inmovilice su vehículo en un extremo de la calzada para la exhibición de la preceptiva documentación tanto del vehículo como del conductor, en aras de comprobar que todo se encuentra correctamente; la información por parte de los agentes actuantes sobre sus derechos y posibles responsabilidades penales en caso de negarse a la realización de la prueba, así como la forma en que habría de llevarse a cabo; el tiempo necesario para realizar de una forma favorable la prueba de alcoholemia con el aparato homologado; e incluso la notificación de una denuncia de tráfico si lo estimase oportuno el agente denunciante, etc ${ }^{66}$.

En rigor, el estado de la cuestión no se circunscribe precisamente sobre el tiempo que deben soportar los conductores en la ejecución de dichas pruebas legalmente establecidas, sino que, para su realización, fuera necesario un tiempo muy superior al estimado en condiciones normales, por ser conducido coactivamente a dependencias policiales.

Es de interés subrayar, en este sentido, lo que la doctrina ha esgrimido. Como el caso de BANACLOCHE PALAO ${ }^{67}$, en cuya monografía asevera que salvo que el conductor se encuentre preventivamente detenido, es actualmente ilegal conducirlo a comisaría; o los autores GARCÍA MORILLO ${ }^{68}$ y DUART ALBIOL ${ }^{69}$, arguyendo la existencia de una evidente irregularidad en el traslado porque parece claramente que se circunscribe a una privación de libertad, es decir, a una situación «intervenida entre la libertad y la detención», o VIDAL PRADO ${ }^{70}$, al indicar, incluso, que no es admisible la falta de oposición del afectado en esta medida para legitimarla. De igual modo

65 Los supuestos de las personas obligadas a realizar las pruebas de alcoholemia a requerimiento de las FCS, se encuentran contempladas en el artículo 21 del RGC.

66 Detalladamente y en otras palabras CASAL HERNÁNDEZ, J.M. (1998), «Derecho a la...», op. cit., p. 262, y BANACLOCHE PALAO, J. (1996), «La libertad personal...», op. cit., pp. 241 y s.

${ }^{67}$ Ibidem, p. 242. Conviene reseñar textualmente una de sus afirmaciones que «si los agentes de tráfico carecieran de aparato medidor del nivel de alcohol en el lugar donde están desempeñando su función, (...) pero no podrán obligarle a dirigirse a una dependencia policial a que practique la prueba de alcoholemia, y ello porque tal actuación carece de todo apoyo legal».

68 GARCÍA MORILLO, J. (1995), «El derecho a...», op. cit., pp. 212 y s.

69 DUART ALBIOL, J.J. (2014), «Inspecciones, registros e...», op. cit., p. 238.

70 VIDAL PRADO, C. (1997), «Algunos límites del...», op. cit., p. 142. 
CASAL HERNÁNDEZ ${ }^{71}$ indica que la medida sería lícita, «si la limitación de la libertad sea interpretada como un consentimiento legitimador de la actuación».

\section{INADMISIBILIDAD DEL TERTIUM GENUS EN EL ÁMBITO DE LA SEGURIDAD VIAL}

\subsection{Falta de previsión legal}

En la actualidad no existe ningún precepto legal ${ }^{72}$ o previsión similar que otorgue la facultad de decisión al colectivo policial sobre esta conducción coactiva. Ni tan siquiera se especifica el lugar o sitio donde realizarlas ${ }^{73}$.

La actual jurisprudencia menor corrobora, a nuestro juicio, las argumentaciones que formuló el Magistrado Julio González Campos en la STC 341/1993 sobre los recursos y las cuestiones de inconstitucionalidad. En el punto tercero de su voto particular, refleja su disconformidad en ciertos aspectos significativos de la sentencia mencionada. Lo que más nos importa destacar se encuentra dirimido cuando el Tribunal lleva a colación que en la citada sentencia «se enfrenta aquí con un grave escollo» al justificar ésta, que la STC 22/1988 ${ }^{74}$ defiende la postura sobre el traslado a dependencias policiales para la práctica de la prueba de alcoholemia, en el sentido, de que no es posible equipararlo con una privación de libertad, a pesar de que se realice en un tiempo estrictamente necesario para llevarla a cabo, y sin embargo, en los traslados a efectos de realizar una identificación en virtud del artículo 20.2 de la LOPSC 1/1992, si constituye una verdadera privación de libertad. Recuerda el Magistrado, y estamos totalmente de acuerdo en su exposición, que en los dos supuestos cuestionados se están utilizando unas medidas idénticas (referida al traslado), a pesar de contener un fin distinto entre ambas (por su propia naturaleza). Por esta razón, no se

71 CASAL HERNÁNDEZ, J.M. (1998), «Derecho a la...», op. cit., p. 266.

72 En este sentido se pronuncia el FJ3 ${ }^{\circ}$ de la SAP de Melilla 55/2019, de 30 de septiembre, [ECLI:ES:APML:2019:158]. También en alusión a la LOPSC 1/1992; FJ1ª de la SAP de Alicante 316/2003, de 11 de junio, [ECLI:ES:APA:2003:2419]; FJ3 ${ }^{a}$ de la SAP de Badajoz 68/2004, de 30 de marzo, [ECLI:ES:APBA:2004:273]; FJ4º de la SAP de Córdoba 38/2000, de 12 de mayo, [ECLI:ES:APCO:2000:764], asevera además que « (...) puesto que esto sólo será a los efectos de practicar diligencias de identificación, supuesto aquí no contemplado». Otras sentencias aluden también a la actual LOPSC 4/2015; FJ2 ${ }^{\circ}$ de la SAP de Palmas de Gran Canaria 217/2017, de 13 de julio, [ECLI:ES:APGC:2017:1710]. Esta sentencia advierte en la doctrina jurisprudencial — concretamente señala la STS 275/2015, de 13 de mayo_- que si un sujeto está perfectamente identificado, el traslado a dependencias policiales constituirá un delito de detención ilegal. Así mismo el FJ3º de la SAP de Barcelona 910/2016, de 15 de noviembre, [ECLI:ES:APB:2016:11709]. Además, BLANCO LOZANO, C. (2005), Tratado de Derecho Penal Español, Tomo 2, Volumen 1, Barcelona, Boch Editor, p. 18, [Consulta: el 26 febrero del 2018]. Disponible en: https://2019.vlex.com/\#vid/delitos-libertad-247164, también establece que la mera retención, como tal, se halla amparada — que no regulada — en la jurisprudencia.

$73 \mathrm{FJ}^{\circ}{ }^{\circ}$ de la SAP de Barcelona 910/2016, de 15 de noviembre, [ECLI:ES:APB:2016:11709].

$74 \mathrm{FJ}^{\circ}$. En el mismo sentido, pero en menor medida menciona el Magistrado a la STC 107/1985. 
puede entender que exista una discrepancia consustancial entre ambas medidas, porque está constituida como una «verdadera identidad entre el supuesto descrito en esta decisión (conducción de una persona a dependencias policiales para la práctica de una diligencia, por el tiempo estrictamente necesario para llevarla a cabo) y el que contempla el art. 20.2 LOPSC ${ }^{75}$.

Una de las tantas aportaciones argüidas por los Tribunales con respecto a que «los agentes de la autoridad no pueden obligar a una persona a realizar una acción que afecte a su libertad, aun cuando sea de una forma leve, si no existe habilitación para ello» ${ }^{76}$, es lo que nos lleva a considerar — como es el caso del traslado a dependencias policiales ex. art. 16.2 de la LOPSC, a los efectos de realizar la diligencia de identificación - la necesidad de incluir esta figura en materia de seguridad vial, con el propósito de satisfacer una norma con rango de ley. Por consiguiente, estamos convencidos, que de esta manera puedan garantizarse, con más rigor, la protección de los derechos fundamentales como ya hizo mención la STC 341/1993 con respecto a los traslados a efectos de identificación. El artículo 17.1 de nuestra Carta Magna establece esta disponibilidad de regular los casos y las formas que proceda una privación de libertad por medio de una Ley Orgánica. En tal sentido hemos incluso de señalar la doctrina asentada por el TC mediante la sentencia 178/1985 cuando argumenta que: «el artículo 17.1 no concibe la libertad individual como un derecho absoluto y no desprovisto de restricciones ${ }^{77}$. Por esa razón, consideramos oportuno aseverar la necesidad de modificar la LECR por medio de una Ley Orgánica ${ }^{78}$ y, por lo tanto, desde dicha perspectiva, pueda ser instrumento válido para limitar los derechos fundamentales que desarrolla la Constitución Española.

75 Punto tercero del voto particular mencionado. MÁLAGA DIÉGUEZ, F. (2001), «Detención y retención», op. cit., p. 143. Dicho autor también es de la opinión, que la retención requiere para ser admisible, de la existencia de una cobertura legal que lo justifique.

${ }^{76} \mathrm{FJ}^{\circ}{ }^{\circ}$ de la SAP de Barcelona 910/2016, de 15 de noviembre, [ECLI:ES:APB:2016:11709], llegando al punto de discernir sobre la legalidad del traslado a dependencias policiales para realizar las pruebas de drogas legalmente establecidas.

$77 \mathrm{FJ}^{\circ}$ de la STC 178/1985, de 19 de diciembre.

78 Ley Orgánica 5/2010, de 22 de junio, por la que se modifica la Ley Orgánica 10/1995, de 23 de noviembre, del Código Penal, en cuyo texto incluyó el legislador la práctica de las pruebas de detección de drogas por test salival, al haber una mayor aflicción de los derechos fundamentales del sujeto concernido. En este mismo sentido se expresa el FJ4º de la STC 341/1993, de 18 de noviembre, en los siguientes términos: «con toda evidencia, estamos, pues, ante uno de los casos a que se refiere el art. 17.1 C.E., cualquiera que sea la disposición de la persona ante la orden recibida, constatación que, por lo demás, da sentido al carácter de Ley Orgánica de este art. 20.2». En parecidos términos se pronuncia JAREÑO LEAL, A. (2019), «La privación de...», op. cit., p. 14. También GARCÍA MORILLO, J. (1995), «El derecho a...», op. cit., p. 49 y BANACLOCHE PALAO, J. (1996), «La libertad personal...», op. cit., p. 238, reconocen que las normas que contengan restricciones de libertad deben de ser no leyes ordinarias, sino leyes orgánicas cuando disertan, precisamente, sobre la práctica de las pruebas de alcoholemia.

(C) UNED. Revista de Derecho Politico

N. ${ }^{\circ} 111$, mayo-agosto 2021, págs. 191-224 


\subsection{Falta de medios de prueba}

El legislador ${ }^{79}$ que redactó ex. art. 16.2 de la LOPSC 4/2015, tuvo a bien ampliar medios de prueba de los ciudadanos como, por ejemplo, la expedición de un volante a la salida de las dependencias policiales que acredite el tiempo de permanencia en comisaría; las causas que motivaron la identificación; el número profesional de los agentes actuantes, entre otras. Todas éstas se suman al requisito de la antigua LOPSC $1 / 1992$, con respecto a la imperativa obligación de las fuerzas y cuerpos de seguridad de rellenar un libro-registro donde se reseñan los asientos relacionados con la seguridad ciudadana ${ }^{80}$.

En consecuencia, nos planteamos lo siguiente: ¿por qué en la figura jurídica de la retención policial a efectos de identificación se expide un volante de salida, y, sin embargo, para realizar una prueba de alcoholemia, la norma no haya previsto ninguna garantía al respecto en las mismas circunstancias? Esta pregunta que en realidad es una afirmación, pone en evidencia la falta de pruebas preceptivas que para el conductor de un vehículo supone ser trasladado a comisaría. Para mayor abundamiento, si realizamos un símil comparativo del traslado originado por una identificación con respecto a la diligencia de alcoholemia, - y debido a que estamos faltos de una previsión legal que justifique esta práctica en materia de seguridad vial—, deducimos que, en tales circunstancias, los agentes actuantes deberían de rellenar un libro-registro, y expedir un volante de salida ${ }^{81}$, entre otras cosas.

Por esta razón los conductores que sean trasladados a dependencias policiales deberían someterse a las exigencias del artículo 17.3, como se cuestionó en el recurso de inconstitucionalidad de la LOPSC 1/1992, y por tanto consideramos la necesidad de tipificarse como tal en una Ley Orgánica, al menos, el derecho de ser informado de forma inmediata y de modo que le sea comprensible sobre las razones y motivos del traslado, reseñando en la diligencia policial la hora en que se efectuó la privación de libertad, así como el número identificativo de los agentes actuantes. A modo colorario, todas estas actuaciones que originen una privación de libertad, y que no estén previstas en la ley, debe constituirse necesariamente como un medio, y no un fin en sí misma ${ }^{82}$ para erigirse lícita desde un prisma constitucional.

79 Reseña MATÍA PORTILLA, F.J. (1997), «El derecho fundamental...», op. cit., p. 244, que el legislador puede prever situaciones no previstas constitucionalmente (refiriéndose a la retención) que entre en juego el orden público y la limitación del ejercicio de los derechos fundamentales.

80 Desde el año 2019 se cumplimenta de forma digital. Lo establece la Instrucción 14/2018, de 27 de diciembre de 2018, de la Secretaria de Estado de Seguridad, por la que se regulan los libros de registros oficiales.

81 JAREÑO LEAL, A. (2019), «La privación de...», op. cit., p. 43.

82 En el mismo sentido, MÁLAGA DIÉGUEZ, F. (2001), «Detención y retención», op. cit., p. 162 y MATÍA PORTILLA, F.J. (1997), «El derecho fundamental...», op. cit., p. 244. 


\subsection{El papel que juega la aquiescencia del sometido para la admisibilidad del traslado}

Aunque constituya un lugar común, queremos disponer de las primeras líneas de este epígrafe para exponer las oportunas cuestiones que plantean las resoluciones judiciales con respecto al consentimiento del conductor cuando se proceda a su traslado: « ¿en calidad de qué fue trasladado el apelante a dependencias policiales? ¿Fue detenido?, ¿se le invitó a que voluntariamente fuera con ellos?, ¿o simplemente se le trasladó dando por hecho el afectado que debía ir sin que se le indicase que estaba obligado a ello?» ${ }^{83}$.

Conviene recordar las afirmaciones que esgrime la STC 341/1993, con respecto a los traslados a efectos de realizar identificaciones, por cuanto contribuirá, como elemento axiológico de contraste, al estudio que juega la voluntariedad del sujeto concernido en las pruebas de alcoholemia. La propia sentencia destaca que no existe una privación de libertad (por tanto, no habrá debate ni siquiera para los traslados en las pruebas de alcoholemia), en la comparecencia espontánea o voluntaria en dependencias, siempre y cuando, el sujeto concernido no esté imposibilitado para abandonar las mismas. Finaliza el Tribunal con respecto a esta idea, que no es el caso del artículo 20.2 de la antigua LOPSC 1/1992. Por consiguiente, la resolución judicial estima que «un acompañamiento a los agentes por orden de ellos (requerimiento), hasta dependencias próximas en las que el sujeto habrá de permanecer, si bien por el tiempo imprescindible para realizar las diligencias de identificación y debe hacerse constar que la desatención a aquella orden conminatoria, se imponga o no por la coacción, puede dar lugar a responsabilidades penales o administrativas. Siendo esto así, la actitud del requerido que acata la orden policial, expresa, claro es, una voluntad (la de no resistirse o no negarse a acompañar a los agentes), pero no necesariamente una voluntad libre en el sentido del art. 17.1 de la Constitución (...) [concluye el tribunal que] una privación de libertad no deja de serlo por el mero hecho de que el afectado la acepte» ${ }^{84}$.

83 FJ $2^{\circ}$ de la SAP de Palmas de Gran Canaria, 217/2017, de 13 de julio, [ECLI:ES:APGC:2017:1710].

$84 \mathrm{FJ}^{\circ}$ de la citada sentencia. En el mismo sentido MÁLAGA DIÉGUEZ, F. (2001), «Detención y retención», op. cit., p. 163, considera la modalidad de privación de libertad en estos supuestos, incluso, cuando el sometido la aceptara. CASAL HERNÁNDEZ, J.M. (1998), «Derecho a la...», op. cit., p. 266, tilda de esta declaración del alto Tribunal de afortunada como un «consentimiento legitimador». De una forma análoga, por todos, nos aclara dicha disertación la STS 275/2015, de 13 de mayo, [ECLI:ES:TS:2011:2072], al sostener un delito de detención ilegal a un agente de la Guardia Civil por trasladar a un sujeto que entró voluntariamente en el vehículo policial. Arguye el alto Tribunal que estamos ante un supuesto donde un agente de la autoridad conmina a la víctima, aprovechándose de su condición de Agentes para introducir en el vehículo a un sujeto a efectos de practicar una identificación. Sigue arguyendo que no se trata de una mera invitación, y el mero dato de no oponer resistencia a la autoridad, aun siendo voluntario, no excluye la conminación o compulsión existente para que así se obre $\left(\mathrm{FJ}^{\circ}{ }^{\circ}\right.$. De igual modo se pronuncia la SAP de Barcelona, 506/2015, de 25 de junio, [ECLI:ES:APB:2015:7726], donde ratifica sobre una infracción de tráfico por no abrocharse el cinturón de seguridad. Tras identificar a los ocupantes del vehículo, los agentes solicitaron al infractor que se desnudara en el vehículo policial. En primera instancia se negó a desprenderse de sus ropas en el interior 
En cualquier caso, y como se ha tenido ocasión de comprobar, para que sea lícito el traslado a dependencias policiales, entre otras $\operatorname{cosas}^{85}$, el conductor del vehículo debe prestar de una forma voluntaria e inequívoca, y sin mediar presión jurídica coercitiva por parte de los agentes, su consentimiento para acompañarles a dependencias policiales (es decir, no cabría informar sobre las consecuencias penales o administrativas si se negara al traslado, para que su decisión no se encuentre coaccionada), siempre y cuando no exista un derecho subjetivo para rechazar la práctica de tales pruebas por los hechos referidos $^{86}$. El consentimiento del afectado tiene que, por ende, ser libre, voluntario e informado para que pueda considerarse como eficaz, de tal modo que incluso permita la posibilidad, por parte del sujeto, de revocar la decisión en cualquier momento de continuar con el proceso policial, si el conductor en cuestión así lo estimara ${ }^{87}$.

Esta situación de libre disposición de un ciudadano, ante un hecho de esta naturaleza, deberá ser reseñada en el atestado policial por los agentes de la autoridad actuantes, habida cuenta de que el acompañamiento a dependencias policiales se colige como un acto voluntario del conductor. Dicho de otro modo, por parte de la jurisprudencia: «si se invita a una persona a que voluntariamente acuda a unas dependencias oficiales, la negativa no puede tener trascendencia. Otra cosa es que en la operativa policial, y ante un supuesto de hecho que por sí mismo justifique y ampare legalmente la detención de una persona, se acuda al recurso de traslado voluntario e interpretación favorable al afectado para evitarle el trance de una formal detención en presencia de terceros, lo que es una cuestión sensiblemente diferente» ${ }^{88}$.

Como consecuencia del criterio expuesto, a nuestro entender, existe una calificación atípica en el delito ex. art.383 del CP — como así lo corrobora la doctrina jurisprudencial $^{89}$ —, si la persona hubiera manifestado su intención inequívoca de realizar

del vehículo policial, sin embargo lo aceptó en dependencias policiales. Finalmente, el fallo condenó a los Guardia Civiles que practicaron dicha diligencia corporal.

85 Además de la necesaria equiescencia del sujeto concernido, el traslado tiene que realizarse conforme a los motivos y razones exigidos por la ley, porque de lo contrario, estaríamos inmersos en el campo de la arbitrariedad, que consecuentemente podría reputarse en un delito de detención ilegal.

86 Difiere en el FJ3 ${ }^{\circ}$ de la SAP de Palma de Mallorca 84/2008, de 05 de mayo, [ECLI:ES:APIB:2008:253], porque el afectado no consienta su traslado para realizar las pruebas, pretextando «cansancio o lo avanzado de la hora nocturna».

87 Este mismo hecho fáctico, fue resuelto por la SAP de Madrid 1182/2011, de 12 de diciembre, [ECLI:ES:APM:2011:18114]. En un primer momento accedió a someterse a las mismas, pero, en el transcurso del traslado a dependencias policiales, modificó su voluntad.

88 FJ $2^{\circ}$ de la SAP de Palmas de Gran Canaria, 217/2017, de 13 de julio, [ECLI:ES:APGC:2017:1710].

89 El FJ $4^{\circ}$ de la SAP de Córdoba 38/2000, de 12 de mayo, [ECLI:ES:APCO:2000:764] califica de legítima, la negativa a desplazarse a comisaría para realizar la prueba de alcoholemia. El FJ2 $2^{\circ}$ de la SAP de Palmas de Gran Canaria 217/2017, de 13 de julio, [ECLI:ES:APGC:2017:1710], califica de improcedente realizar la segunda prueba en dependencias policiales, cuando el etilómetro se había quedado sin batería, quedando probado que el conductor únicamente se negó a ser trasladado. La SAP de Alicante 316/2003, de 11 de junio, [ECLI:ES:APA:2003:2419], establece que negarse a ser trasladado a dependencias policiales para realizar las pruebas de alcoholemia, exonera de culpa por el posible delito de desobediencia a su 
la prueba de alcoholemia, y únicamente se negara a desplazarse a un lugar distinto del requerimiento. Pues bien, en tales circunstancias, no puede considerarse «que se conculcó el principio de autoridad al negarse a una prueba obligatoria, sino simplemente a que se negaba a hacerla en esas circunstancias en las que se imponían restricciones a su libertad personal» ${ }^{90}$.

\subsection{El principio de proporcionalidad y menor aflictividad para terceros}

No debemos de olvidar los principios rectores de obligado cumplimiento que envuelven a las fuerzas y cuerpos de seguridad en el ejercicio de sus funciones. Dicho lo cual, en el artículo 5.2.C de la LOFCS reza que «en el ejercicio de sus funciones deberán actuar con la decisión necesaria, y sin demora cuando de ello dependa evitar un daño grave, inmediato e irreparable; rigiéndose al hacerlo por los principios de congruencia, oportunidad y proporcionalidad en la utilización de los medios a su alcance». La aplicación de estos principios conlleva hacer un uso ponderado cuando se practiquen las pruebas de alcoholemia, tratando de evitar al sometido cuantas molestias o daños pudieran acarrearle.

La doctrina científica ${ }^{91}$ ha configurado el principio de proporcionalidad como un requisito esencial para legitimar muchas actuaciones policiales controvertidas. La pro-

sometimiento, por la imposición de una carga adicional al conductor interceptado $\left(\mathrm{FJ} 1^{\circ}\right)$. La SAP de Melilla 55/2019, de 30 de septiembre, [ECLI:ES:APML:2019:158] en su FJ3º, realiza detenidamente una argumentación sobre la atipicidad de la negativa en estos supuestos. El FJ1 ${ }^{\circ}$ de la SAP de Barcelona 910/2016, de 15 de noviembre, [ECLI:ES:APB:2016:11709], en el traslado a fin de determinar las pruebas para realizar el test salival. La SAP de Alicante 500/2004, de 20 de octubre, [ECLI:ES:APA:2004:2339], por su parte, expresa en el FJ1 $1^{\circ}$, que el traslado a efectos de realizar las prueba de alcoholemia «supone una irregularidad que puede repercutir, en su caso, en la impunidad de su negativa al sometimiento de la prueba en esas condiciones espacio temporales». La SAP de Almería 26/2001, de 29 de enero, [ECLI:ES:APAL:2001:96], exonera de culpa por un delito de desobediencia ex. Art. 380 por «no ofrecer elementos de convicción suficientes dadas las circunstancias concurrentes [refiriéndose al traslado irregular para realizarlas]» $\left(\mathrm{FJ}^{\circ}\right.$ ). También llega a confirmar la absolución por un delito de negativa ex. art. 383 del CP, la SAP de Sevilla 635/2014, de 27 de noviembre, [ECLI:ES:APSE:2014:3671].

$90 \mathrm{FJ}^{\circ}$ de la SAP de Badajoz 68/2004, de 30 de marzo, [ECLI:ES:APBA:2004:273]. En este supuesto, la patrulla solo disponía del etilómetro de muestreo en la vía pública, motivo por el cual fue invitado a trasladarse a comisaría para efectuar la prueba con un etilómetro evidencial. El FJ1 ${ }^{\circ}$ de la SAP de Almería 26/2001, de 29 de enero, [ECLI:ES:APAL:2001:96], y el FJ4º de la SAP de Córdoba 38/2000, de 12 de mayo, [ECLI:ES:APCO:2000:764] argumentan en un mismo sentido.

91 BANACLOCHE PALAO, J. (1996), «La libertad personal...», cit. p. 248; GÓMARA HERNÁNDEZ, J.L., y AGORRETA RUIZ, D. (2007), Prontuario de Seguridad Pública e Intervención Policial, Pamplona, Dapp publicaciones jurídicas, p. 490; y DUART ALBIOL, J.J. (2014), «Inspecciones, registros e...», op. cit., p. 248. GONZÁLEZ MONTES, F. (2007), «Especialidades procesales en...», op. cit., p. 607, es partidario para cuando se practique la prueba de alcoholemia, se cumpla el principio de proporcionalidad en atención a la mínima incidencia en el derecho a la libertad de movimientos frente a los intereses jurídicos. MÁLAGA DIÉGUEZ, F. (2001), «Detención y retención», op. cit., p. 143, expresa que la legitimidad de la retención, lleva consigo el necesario cumplimiento del principio de proporcionalidad, la existencia de cobertura legal y la evitación de cualquier peligro de arbitrariedad.

(C) UNED. Revista de Derecho Politico

N. ${ }^{\circ} 111$, mayo-agosto 2021, págs. 191-224 
yección que tiene sobre la diligencia policial en el ámbito de la seguridad vial es de vital importancia, porque es capaz de operar en el justo equilibrio entre los fines que persigue (realizar la prueba de alcoholemia) y los perjuicios que comportan a la persona sometida al traslado (la privación de libertad). En este sentido, la doctrina jurisprudencial $^{92}$ también ha dilucidado sobre este principio, reseñando que se deben cumplir y reunir los criterios de idoneidad, necesidad y proporcionalidad en sentido estricto.

No obstante lo anterior, resulta de interés la idea construida por la Audiencia Provincial con respecto a los traslados a fin de verificar la tasa de alcohol, arguyendo que: «no se trata de establecer un protocolo de las FCS que controlen la regularidad del tráfico rodado contar con un etilómetro para realizar esa comprobación en el lugar de ocurrencia de los hechos; es que es dudoso que (...) [refiriéndose al principio de proporcionalidad y al de menor aflictividad para terceros], se pueda cargar a la persona investigada con una incomodidad derivada sólo de la imprevisión de los miembros de aquéllas $(\ldots)^{93}{ }^{»}$.

También es importante destacar el papel que juegan las Instituciones públicas para minimizar la aflictividad de los conductores. Numerosas sentencias de la jurisprudencia, establecen sobre la incapacidad de la Administración ${ }^{94}$ para resolver o sufragar gastos o medios profesionales - tanto cuantitativos como cualitativos- en la práctica de la prueba de alcoholemia, tildándola como una auténtica irregularidad ${ }^{95}$. Dicho extremo presenta no pocos problemas, puesto que ponen en duda la legitimidad de los agentes en su forma de actuar. Es por ello, que consecuentemente el contexto de esta situación genera un problema evidente, visto que los agentes tienen la obligación de someter al conductor a las pruebas preceptivas de alcoholemia, y, por otro lado, las Instituciones deben poner «los medios en circunstancias acordes con la libertad de la persona que aquí ha de ser primada ${ }^{96}$.

Somos de la opinión que la Administración tiene la obligación de sufragar todos aquellos medios necesarios, en atención a preservar una menor aflictividad propiamente dicho, y por tanto no puede «imponer a los ciudadanos cargas innecesarias para el cumplimiento de la obligación del sometimiento de las pruebas de alcoholemia;

Por su parte, JAREÑO LEAL, A. (2019), «La privación de...», op. cit., p. 15, arguye para que se cumpla dicho principio es importante que se limite las actuaciones, refiriéndose a los traslados a efectos de prevenir infracciones administrativas. En el mismo sentido ASENCIO MELLADO, J.M. (1994), «La detención a...», op. cit., p. 38, menciona que debe respetarse el principio de excepcionalidad en la norma cuando se practiquen los traslados a efectos de identificación.

92 Por todas, mencionamos la STC 207/1996, de 16 de diciembre.

$93 \mathrm{FJ}^{\circ}$ de la SAP de Madrid 1467/2012, de 14 de noviembre, [ECLI:ES:APM:2012:18495].

${ }^{4} \mathrm{FJ}^{\circ}{ }^{\circ}$ de la SAP de Palma de Mallorca 84/2008, de 05 de mayo, [ECLI:ES:APIB:2008:253], FJ3 ${ }^{\circ}$ de la SAP de Badajoz 68/2004, de 30 de marzo, [ECLI:ES:APBA:2004:273] y FJ1 ${ }^{\circ}$ de la SAP de Almería 26/2001, de 29 de enero, [ECLI:ES:APAL:2001:96].

95 En términos semejantes se pronuncian; la SAP de Alicante 500/2004, de 20 de octubre, [ECLI:ES:APA:2004:2339] (FJ1 ${ }^{\circ}$ ), y la SAP de Palmas de Gran Canaria 217/2017, de 13 de julio, [ECLI:ES:APGC:2017:1710] $\left(\mathrm{FJ}^{\circ}\right)$.

$96 \mathrm{FJ}^{\circ}{ }^{\circ}$ de la SAP de Córdoba 38/2000, de 12 de mayo, [ECLI:ES:APCO:2000:764]. 
de forma que la negativa a realizarlas fuera del lugar de los hechos podrá exonerar de culpa por el posible delito de desobediencia» ${ }^{97}$.

\subsection{La existencia de un interés o exigencia pública que justifique el traslado}

Ante las imprecisiones que acabamos de exponer en el epígrafe anterior, podemos preguntarnos cuáles son los motivos que condicionan a los Tribunales para no condenar a los agentes de la autoridad por un delito de detención ilegal ${ }^{98}$, si realmente no existe previsión legal en una norma que lo justifique. En consideración, estamos a favor de dicho extremo, porque pese a que dicha figura no se encuentra tipificada en el ordenamiento jurídico — recordemos que el objeto a estudio se centra en materia de la seguridad vial_-, estas actuaciones, a priori, adolecen de ser intervenciones ilegales, siempre que se realice dentro del marco y los requisitos legalmente establecidos (según el RGC). En otras palabras, no se producirá un ilícito penal regulado en la norma punitiva, siempre que el traslado no sea motivado con un propósito caprichoso, aleatorio o arbitrario. No obstante lo anterior, opinamos que esta situación pone en jaque a los Tribunales conocedores de la existencia de un vacío legal ante tales vicisitudes como las expuestas en el desarrollo de este trabajo.

La casuística sobre los traslados a fin de practicar la prueba de alcoholemia es copiosa en atención al fin perseguido como veremos a continuación. En este sentido nos dispondremos a desgranar supuestos fácticos que tantos problemas puede generar en el ámbito jurídico, y cómo no, en la forma de actuar de los agentes encargados de la vigilancia del tráfico. El primero de ellos consiste en las pruebas practicadas bajo el amparo de los programas de controles preventivos, ordenados por la autoridad competente, y regulados en la dicción literal ex. art. 21.d del RGC.

Sobre el particular, la praxis policial, por tanto, consiste en ordenar a los conductores que se apeen a un lado de la calzada a fin de practicar dicha prueba pericial, sin otro motivo aparente, que ir filtrando vehículos al azar. Todo ello sin perjuicio que, en el desarrollo de la misma, aparezcan otras circunstancias sobrevenidas que justifique la elección de otro vehículo en concreto para su debida comprobación.

Dicho lo cual, la práctica de dichas pruebas se realizará de forma aleatoria, sin que tengan que concurrir sospechas fundadas o indicios racionales de que el conductor pueda arrojar un resultado superior al permitido (RGC), en aras de sancionar una infracción administrativa; o bien penal si llegados al caso, superase la tasa legalmente permitida de $0.60 \mathrm{mg} / \mathrm{l}$ que refiere ex. art. $379.2 \mathrm{del} \mathrm{CP}$. No obstante, es preciso destacar también que en los controles preventivos es habitual que los sometidos realicen un primer soplado utilizando el etilómetro de muestreo de dotación, y en caso

$97 \mathrm{FJ}^{\circ}{ }^{\circ}$ de la SAP de Alicante 316/2003, de 11 de junio, [ECLI:ES:APA:2003:2419].

98 Nos recuerda BLANCO LOZANO, C. (2005), «Tratado de derecho...», op. cit., p. 18, para que se produzca una detención ilegal, en términos jurídicos se necesita un dolo muy específico que implique la conciencia plena, absoluta y segura que la privación de libertad es ilegal y no ajustada a derecho.

(C) UNED. Revista de Derecho Politico

N. o 111, mayo-agosto 2021, págs. 191-224 
de arrojar un resultado inferior a la tasa permitida por el RGC, los agentes indicarán al conductor que continúe la marcha. Sin embargo, cuando la prueba arroje unos parámetros superiores de lo legalmente permitido, los agentes precisarán, entonces, de un etilómetro evidencial.

No es frecuente - a pesar de que en la actualidad ocurre en municipios con escasos recursos económicos-, que los agentes realicen estos controles preventivos teniendo emplazado en dependencias policiales el etilómetro evidencial. Por este motivo, las fuerzas y cuerpos de seguridad deben ser cautelosos, puesto que consideramos que esta praxis policial quedaría mermada por razones obvias tanto en la operativa policial ${ }^{99}$, como en el manifiesto atropello del derecho a la libertad sobre los conductores, al quebrantarse el principio de proporcionalidad en atención al juicio de necesidad. Entendiendo éste como aquel medio escogido por parte de la Policía para alcanzar el fin legítimo perseguido, de forma que no constituya una lesión de los derechos fundamentales de la persona ${ }^{100}$; así como el juicio de idoneidad, el cual nos informa de la adecuación de la medida «para alcanzar el fin constitucionalmente perseguido» ${ }^{101}$ por afectar al tiempo de duración o incluso la intensidad ${ }^{102}$, como es el caso.

Así con todo, y llegados al punto de concurrir los hechos acaecidos, pueden subyacer dos situaciones de diferente naturaleza ${ }^{103}$. La primera de ella concierne cuando una vez practicada la prueba con el etilómetro de muestreo arroje un resultado comprendido entre una tasa que supere el umbral de lo permitido por el RGC ${ }^{104}$, pero inferior a la tasa que limita el Código Penal (tasa superior de $0.60 \mathrm{mg} / \mathrm{l}$ de aire espirado). De modo que se derive una actuación policial con el objetivo de perseguir y sancionar una infracción de naturaleza administrativa. Llegados a este punto, cabe preguntarse si el principio de proporcionalidad quedaría mermado o quebrantado ante estos hechos, al cuestionar el justo equilibrio del perjuicio causado al conductor cuando se le priva de su libertad, con respecto a los beneficios para la Administración que espera conseguirse mediante esta diligencia policial (es decir, sancionar una infracción de tráfico con tildes administrativos). A nuestro entender, existe una disonancia entre el fin perseguido y los medios utilizados para llegar a su alcance, lo que a nuestro juicio quebranta el principio de proporcionalidad. A este respecto señala, VIDAL PRADO al esgrimir la posibilidad de imponer una sanción de este calibre (refiriéndose a los traslados para realizar las pruebas de alcoholemia) cuando el conductor del vehículo sometido no hubiera protagonizado ninguna infracción ni

99 Entre otras cosas, por la evidente necesidad de trasladar al sometido a comisaría donde se encuentra el etilómetro evidencial.

100 Véase la STC $137 / 1990$, de 19 de julio $\left(\mathrm{FJ7}^{\circ}\right)$.

101 FJ4º de la STC 207/1996, de 16 de diciembre. También lo indica ALFONSO PÉREZ, F. (2004), Manual del policía, Madrid, La Ley Actualidad, $4^{\circ}$ Edición, p. 501.

102 DUART ALBIOL, J.J. (2014), «Inspecciones, registros e...», op. cit., p. 378.

103 Recordamos que el análisis de este supuesto, parte de la premisa que el traslado se realice sin que la persona haya sido detenida formalmente por un delito contra la seguridad vial u de otra naturaleza.

104 Hay que tener en cuenta, que la tasa mínima que establece el RGC, variará en atención a la categoría del permiso de conducción. 
provocado accidente alguno. Pero más importante nos resulta los argumentos utilizados en su obra al discrepar sobre el hecho de trasladar al conductor de un vehículo a dependencias policiales para realizar la prueba de alcoholemia con fines administrativos porque: «en estos supuestos no parece que el resultado positivo pueda considerarse un indicio de criminalidad suficiente para privar de liberad a una persona, porque estaríamos de nuevo ante un ilícito administrativo» ${ }^{105}$.

La Audiencia Provincial de Badajoz se pronunció sobre unos hechos similares —dado que no estaba acreditado que la conducción del infractor se hubiese producido bajo las influencias de bebidas alcohólicas-, consistentes en una conducción anómala por circular con un vehículo en sentido contrario. La Policía Local trasladó al infractor a las dependencias policiales de la Guardia Civil a fin de realizar la prueba de alcoholemia. La sentencia ratifica la absolución del Juzgado a quo (de lo Penal de Mérida) por desobediencia a realizar las pruebas de alcoholemia, a pesar de que en las dependencias de la benemérita, el soplido fue insuficiente y erróneo. En la exposición de las argumentaciones jurídicas, no se entra a dilucidar sobre el núcleo de la cuestión, aunque sí menciona su disconformidad por enmarcarse en una práctica irregular al carecerse de una cobertura jurídica expresa. Con esta idea queremos decir que los controles preventivos de alcoholemia que necesariamente generen un traslado, no deberían realizarse con la única finalidad de perseguir una infracción administrativa ${ }^{106}$.

\section{LA ADMISIBILIDAD EN LA INVESTIGACIÓN EX. ART. 379.2}

Otra de las situaciones conforme al supuesto anterior trata sobre la investigación de hechos que revistan un carácter delictivo en el ámbito de la seguridad vial. Nos estamos refiriendo al supuesto de que un conductor arroje una tasa superior a la legalmente establecida ex. art. 379.2 del CP mediante un etilómetro de muestreo, de modo que la actuación policial quedaría circunscrita en el marco de una investigación de naturaleza penal. Por esa razón, consideramos que este caso dista considerablemente de la mera sanción de una infracción administrativa.

Para entender la importancia de los argumentos que a continuación vamos a exponer, proponemos un hecho fáctico que, asiduamente, concurre en materia relacionada con los delitos contra la seguridad vial. Imaginemos que una patrulla encargada de la vigilancia del tráfico, adolece de un etilómetro evidencial en el coche patrulla (únicamente tiene como dotación un etilómetro emplazado en dependencias policiales), y dentro de los requisitos exigidos por el RGC, son requeridos para que se personen en el lugar de los hechos, en aras de someter al conductor de un vehículo

105 VIDAL PRADO, C. (1997), «Algunos límites del...», op. cit., p. 133.

106 JAREÑO LEAL, A. (2019), «La privación de...», op. cit., pp. 15 y s., cuando dilucida sobre el art. 16.2 de la LOPSC, argumenta que la tarea de prevención en el ámbito policial sólo puede referirse a la prevención de delitos, por tanto excluye expresamente cuando la intención sea la de prevenir infracciones administrativas. 
a la prueba de alcoholemia. La prueba realizada con el etilómetro de muestreo, arroja una tasa superior a $0.60 \mathrm{~m} / \mathrm{gl}$ de aire espirado, sin apreciarse a priori que su conducción haya podido verse mermada por sus facultades psicofísicas, es decir, que no se aprecia que el individuo en cuestión se encuentre bajo la influencia de bebidas alcohólicas. El procedimiento habitual de los agentes consistirá en el traslado del mismo a dependencias policiales con el propósito de determinar mediante el auxilio de un etilómetro evidencial, el resultado de las dos pruebas legalmente establecidas, a fin de conocer el resultado final. De manera que, dependiendo de la cantidad de alcohol que arroje finalmente utilizando un etilómetro homologado, nos encontraríamos ante un delito contra la seguridad vial por superar la tasa legalmente permitida, o bien, ante una sanción administrativa.

Ante la evidente posibilidad de encontrarnos con la existencia de un hecho delictivo, entendemos que el principio de proporcionalidad, se encontraría en menor medida afectada, habida cuenta de que el fin legítimo que se pretende perseguir dista considerablemente de una mera infracción administrativa.

Los defensores en llevar a cabo el traslado a dependencias policiales negándole la categoría de una verdadera detención, evidentemente, subsumidos en una clara voluntad de no perjudicar al encartado, podría resultar paradójico ${ }^{107}$ en cuanto a la forma de proceder, pudiendo incluso producirse un efecto contrario al que se pretende proteger. En este sentido, argumentamos que, si el conductor es trasladado a dependencias policiales en calidad de detenido, sería admisible una amalgama de derechos que reconoce el artículo 520 de la LECR. Sin embargo, la situación fáctica de conducir a dependencias policiales al conductor de un vehículo sin constituir una detención en sentido estricto, además de erigirse como una verdadera privación de libertad, supondría para el afectado un evidente menoscabo del reconocimiento de sus derechos fundamentales ante un posible abuso o extralimitación policial llegados al caso.

Veamos, pues, lo que los Tribunales han referido sobre los traslados conforme a otras figuras jurídicas de similar naturaleza. Por ejemplo, dilucida el TS con respecto al traslado de una mujer a dependencias policiales justificado por el hecho de que fuera cacheada por un agente del mismo sexo, al haber indicios racionales para creer en la existencia de un hecho con carácter de delito relacionado con el tráfico de droga. Pues bien, el Magistrado esgrimió que «el derecho a la libertad no ha sido conculcado por una diligencia policial de cacheo, aunque ella suponga la inmovilización del ciudadano durante el tiempo imprescindible para su práctica que, en este caso, por

107 En términos similares, MÁLAGA DIÉGUEZ, F. (2001), «Detención y retención», op. cit., pp. 179 y s., en cuyos argumentos hace mención con respecto a la figura jurídica del traslado a efectos de practicar una identificación. No es menos cierto que, a pesar de la semejanza en su disertación, se aprecia una diferencia con respecto a los traslados que se realicen en el ámbito de la seguridad vial, habida cuenta de que la diligencia de identificación, se encuentra regulada en el artículo 16.2 de la actual LOPSC, y por tanto el legislador ha incorporado de garantías ante tal propósito. 
ser una mujer la sospechosa, hubo de ser realizada necesariamente en las dependencias policiales próximas al lugar de la detención» ${ }^{108}$.

De igual modo, conviene traer a colación la doctrina sentada a todos los efectos por la figura jurídica consistente en desnudar de forma parcial o integral a un sujeto que no se le haya privado de su libertad, coincidiendo con la idea de que solamente vendría justificada dicha medida de prospección corporal en el seno de investigaciones delictivas ${ }^{109} \mathrm{o}$, en las labores propias de indagación y prevención por parte de los miembros de las Fuerzas y Cuerpos de Seguridad. En cambio, para doblegar el derecho fundamental de la intimidad corporal del sometido, además de lo anterior, se exige como imprescindible, la constatación de unas pruebas objetivas y con un grado razo-

$108 \mathrm{FJ}^{\circ}{ }^{\circ}$ de la STS n ${ }^{\circ}$ rec. 1271/1994, de 23 de diciembre, [ECLI:ES:TS:1994:8883]. Con respecto al traslado a dependencias policiales para realizar cacheos con el fin de preservar la intimidad de la persona, o porque se encuentra en comisaría un profesional del mismo sexo que el sometido, véase la STS nºrec. 475/1994, de 23 de febrero, [ECLI:ES:TS:1994:1164] (FJ único), relacionado con agentes de policía integrados en el grupo antidroga, cuya actuación consistió en el traslado de una mujer a fin de practicar un cacheo por las sospechas sobrevenidas, de un delito contra la salud pública. Se procedió a identificar a la acusada por la forma de reaccionar, del nerviosismo impropio y al no dar una explicación satisfactoria de su presencia en la ciudad. La STS 610/1994, de 30 de junio, [ECLI:ES:TS:2010:3676] legitima el traslado de una persona a dependencias policiales con intención de practicar un registro personal mucho más exhaustivo. Sigue argumentando la sentencia que, en el desarrollo del traslado, dicha persona se revolvió contra un agente que le custodiaba en el asiento trasero policial. Finalmente, se le intervino droga escondida dentro de una zapatilla. Y por último la STS 1347/2011, de 30 de noviembre, [ECLI:ES:TS:2011:8999] $\left(\mathrm{FJ}^{\circ}\right.$ ), resuelve un caso similar sobre la policía nacional de Valencia. Los agentes observan en actitud nerviosa a una persona, y como quiera que existía mucha gente en la estación de autobuses, le requirieron para que los acompañara a dependencias policiales, donde finalmente fue detenida por encontrar droga junto al bolsillo del pantalón.

109 En este sentido se pronuncia la STS 677/2009, de 16 de junio, [ECLI:ES:TS:2009:4471], en cuyos hechos fácticos relata que la Guardia Civil somete a un individuo a un desnudo integral durante 10 minutos, sin que concurran indicios o sospechas para justificar dicho sometimiento. Los agentes finalmente fueron condenados por un delito contra la integridad moral y por una detención ilegal. Además, por su perspicuidad, nos resulta interesante destacar las valoraciones jurídicas insertadas en el $\mathrm{FJ}^{\circ}$ de la AP de Barcelona, en referencia, a los hechos acaecidos que motivaron el enjuiciamiento de unos agentes de la Policía Local de Rubí por un delito contra la integridad moral, porque de una forma aleatoria, habían decidido someter a un desnudo integral a una persona en el interior del vehículo policial. Dicho lo cual, arguye el Tribunal que «su realización [el desnudo integral] solamente vendría justificada en el seno de investigaciones delictivas, y ante evidencias serias de que se trata de registros que han de arrojar algún tipo de resultado en el curso de investigaciones abiertas, porque abriguen sospechas fundadas de que el sometido al registro oculte elementos relacionados con el delito en zonas corporales íntimas a las que no es posible acceder sin esa modalidad de registro». También el FJ1 $1^{\circ}$ de la SAP de Barcelona, 506/2015, de 25 de junio, [ECLI:ES:APB:2015:7726] confirmada por el Auto del TS 682/2016, de 31 de marzo, [ECLI:ES:TS:2016:3906A]. Por hechos similares, se pronuncia la STS 677/2009, de 16 de junio, [ECLI:ES:TS:2009:4471]; el ATS 1554/2003, de 26 de septiembre, [ECLI:ES:TS:2003:9626A]; y la STS 156/2013, de 7 de marzo, [ECLI:ES: TS:2013:919]. La SAP de Barcelona, 132/2012, de 5 de diciembre, [ECLI:ES:APB:2012:13715], esgrime que en el transcurso de quitarle una camiseta y bajarse los pantalones, conlleva la obligación y exigencia de sospecha por un delito. El ATS 1474/2005, de 28 de junio, [ECLI:ES: TS:2005:8428A], esgrime que resulta proporcional la medida de desnudar a un sujeto, en atención a la gravedad del delito que se persigue.

(C) UNED. Revista de Derecho Politico

N. o 111, mayo-agosto 2021, págs. 191-224 
nable de determinación para cerciorarse de que, incluso, el desnudo va a arrojar algún tipo de resultado ${ }^{110}$. Como se colige en las resoluciones que se han expuesto por parte de la doctrina jurisprudencial, a modo de analogía, defendemos que cuando las fuerzas y cuerpos de seguridad se vean en la tesitura de trasladar a alguien a comisaría a efectos de practicar la prueba de alcoholemia, disponiendo de indicios racionales de que los hechos pudieren reputarse como delictivos, la actuación policial estará ajustada a derecho. Además, hemos de tener en cuenta que debe resultar necesario utilizar esta medida para las labores de investigación penal. En atención a lo cual, la conducción a comisaría no puede estar basada en indicios superfluos, sino más bien todo lo contrario. Es decir, que su justificación venga sustentada por una base fáctica objetiva como indica el artículo 492.4 de la LECR (motivos racionalmente bastante para creer en la existencia de un hecho que presente los caracteres de delito): la existencia de una indubitable posibilidad de que el conductor vaya a arrojar un resultado superior al marcado por el Código Penal.

Por tanto, los indicios racionales deben ser lo suficientemente contundentes, como para pensar que la persona va a superar la tasa legalmente permitida por la norma coercitiva (en el etilómetro de muestreo, y aunque no se pueda determinar la influencia, los agentes se percaten de ello a través de signos muy leves externos como son la halitosis alcohólica, las pupilas algo dilatadas, etc). Cabría en tales circunstancias plantearse la posibilidad de que, independientemente de que el sujeto concernido preste o no su voluntad a ser trasladado, se conduzca a comisaría, pero, esta vez, en calidad de detenido ${ }^{111}$ en virtud del artículo 492.4 de la LECR. Ahora bien, opinamos que lo más idóneo es acudir al traslado voluntario como se ha analizado con la finalidad de favorecer al afectado, y de este modo «evitar el trance de una formal detención en presencia de terceros, lo que es una cuestión sensiblemente diferente» ${ }^{112}$, toda vez que las FCS se encuentran en la tesitura de perseguir delitos en el ejercicio de sus funciones, y, por otro lado, la de garantizar los derechos de la persona.

110 La STS 941/2012, de 29 de noviembre, [ECLI:ES:TS:2012:7979], la STS 677/2009, de 16 de junio, [ECLI:ES:TS:2009:4471], y la SAP de Barcelona, 506/2015, de 25 de junio, [ECLI:ES:APB:2015:7726], confirmada ésta última por el Auto del TS 682/2016, de 31 de marzo, [ECLI:ES:TS:2016:3906A].

111 La SAP de Melilla, 24/2008, de 21 de mayo, [ECLI:ES:APM:2008:107], con respecto al desnudo integral en dependencias policiales, establece que una vez se constate indicios racionales de que un sujeto porte droga en su cuerpo, lo más aconsejable en estos casos «hubiera sido primero detenerlo, instruirle de sus derechos, ponerlo bajo custodia para evitar que se desprendiera de la sustancia que presumiblemente portaba y dar cuenta a la autoridad judicial para que proveyera lo oportuno sobre el cacheo» $\left(\mathrm{FJ}^{\circ}\right.$ ). En un mismo sentido, y ante la constatación de la ocultación de un envoltorio en los genitales se pronuncia el FJ2 ${ }^{\circ}$ de la STS 941/2012, de 29 de noviembre, [ECLI:ES:TS:2012:7979].

112 SAP de Las Palmas de Gran Canaria, 217/2017, de 13 de julio $\left(\mathrm{FJ}_{2}^{\circ}\right.$ ). 


\section{A MODO DE CONCLUSIÓN}

Sobre la base de los argumentos que hemos ido esgrimiendo a lo largo de este breve pero compacto estudio, estamos en disposición de efectuar las siguientes conclusiones.

Sin ir más lejos, y como hemos tenido ocasión de comprobar, la retención policial se configura como una inevitable consecuencia surgida de determinadas diligencias policiales, concretamente nos estamos refiriendo a aquellas de carácter momentáneo, cuya práctica se prolongue durante un corto espacio de tiempo relacionadas con la inmovilización o privación de la libertad ambulatoria de un individuo que debiere ser sometido a éstas. Ahora bien, cuando esta figura jurídica deba prolongarse más allá de las previsiones normales que estima la propia norma — debido, por ejemplo, al traslado del mismo a dependencias policiales a fin de que se le practique una prueba de alcoholemia-, habrán de concurrir en estas formas de retención, al menos, unas mínimas garantías que amparen los derechos de quien se viera implicado en tal situación.

De este modo, aunque la afectación del derecho a la libertad, en estos casos, no se vea menoscabada al mismo grado o nivel que en una detención propiamente dicha, no es menos cierto que, a instancias del TC, estas situaciones de retención sí han sido denominadas sin tapujos por el alto Tribunal como una «privación de libertad». Y precisamente, la citada doctrina jurisprudencial es la que evidencia una paradoja en relación a los traslados llevados a cabo para realizar las pruebas de alcoholemia, en el sentido de que estas situaciones adolecen de todas las garantías y los derechos que la propia LOPSC 4/2015 sí confiere, por el contrario, para las identificaciones policiales. Por consiguiente, respecto a este asunto, consideramos imprescindible y necesario que se realice inminentemente una regulación normativa que satisfaga el rango de ley para la figura de la retención policial en la práctica de las pruebas de alcoholemia, y la cual aborde cuantas garantías sean oportunas para el propio sometido que fuere trasladado a comisaría, de modo que resulte lícito su ejecución sin lugar a interpretaciones que pudieran causar ya no solo la indefensión jurídica del afectado, sino también la sensación de inseguridad jurídica del propio agente de la autoridad que, en su deber, se viera obligado, por las circunstancias de la intervención policial, a llevarlo a la práctica a fin de esclarecer unos hechos que pudieren constituir un ilícito penal contra la seguridad vial. Y, a nuestro juicio, todo ello quedaría resuelto, no nos cabe duda de ello, si esta figura fuese desarrollada definitivamente en una ley.

En cualquier caso, mientras no se regule dicha figura jurídica en el ámbito de la seguridad vial, conviene traer a colación la línea doctrinal sentada hasta la fecha por la jurisprudencia respecto a este asunto en sus decisiones judiciales. Concretamente entre éstas se ha estipulado, por ejemplo, el sobreseimiento definitivo a favor de un conductor que se negó a ser trasladado a comisaría a fin de realizársele las pruebas de alcoholemia, basado en la causal de atipicidad del art. 383 de nuestra norma punitiva. Sería importante, por tales motivos, que llegaran dichos procesos al TS para el oportuno pronunciamiento que dirimiera, de una vez para siempre, esta controversia; pues se está generando en muchas resoluciones judiciales una tendencia alcista estimando

(C) UNED. Revista de Derecho Politico

N. ${ }^{\circ} 111$, mayo-agosto 2021, págs. 191-224 
esta práctica policial como irregular. Aunque hemos de manifestar que en este caso concreto estamos de acuerdo.

Resulta más que pertinente realizar una reflexión sobre el estudio realizado por la doctrina jurisprudencial de esta figura jurídica con ocasión de otras acciones policiales, cuyos fines perseguidos difieren al respecto, pero sirven como elemento axiológico de contraste. Entre ellas destacamos la práctica policial consistente en trasladar a una persona para realizarle un cacheo policial, semidesnudo o desnudo integral, y que al igual como sucede con los traslados para verificar la tasa de alcohol, también carecen de una consolidación normativa (recordemos que el status libertatis tampoco ha sido modificado). Asimismo, nos hemos apoyado para su estudio en los traslados a efectos de identificación, tanto lo recogido para tal fin en el art. 16.2 de la actual LOPSC como en la STC 341/1993. Como fruto del análisis de dicha comparativa se han extraído los siguientes extremos: el principio de proporcionalidad se erige como un principio de construcción jurisprudencial capaz de operar como pauta de actuación al indicarnos la necesidad de guardar un justo equilibrio entre los beneficios que se han de obtener al realizar la prueba de alcoholemia y, por otra parte, los perjuicios que la misma pudieran comportar al conductor al ser trasladado a dependencias policiales. Partiendo del referido principio, podemos señalar que no se atisba razón alguna que justifique el traslado forzoso del conductor por la mera sospecha de que hubiera infringido una simple infracción administrativa, como tampoco creemos que sea ecuánime ni prudente, organizar un dispositivo policial para llevar a cabo un control estático o preventivo de alcoholemia en la vía pública, cuando no se disponga del correspondiente etilómetro evidencial portátil, ya que consideramos que este proceder constituiría un caprichoso atropello premeditado contra el derecho a la libertad.

A pesar de lo manifestado en párrafos anteriores, defendemos, por el contrario, la postura de trasladar a un conductor para efectuarle un test de alcoholemia cuando se hallen indicios racionales de que éste pudiere arrojar una tasa superior a la permitida según el Código Penal, es decir que el sujeto en cuestión fuera sospechoso de haber cometido una infracción penal. Con ello estamos en disposición de aseverar que los traslados de esta naturaleza no lesionaría, por consiguiente, el derecho a la libertad, siempre y cuando, eso sí, se abordara desde el prisma de la investigación de un delito contra la seguridad vial, tal y como establece ex. art. 379 de la norma punitiva y, por qué no, cuando se tuvieran indicios racionales de que el conductor fuera a arrojar una tasa superior a $0.60 \mathrm{mg} / \mathrm{l}$, que es la indicada por nuestra norma coercitiva, cabría incluso la posibilidad de realizar el traslado policial del sujeto en calidad de detenido, como indica ex art. 492.4 de la LECR.

En virtud de lo cual, — tanto para sancionar una infracción administrativa como penal-, sirva siempre de garantía constitucional para efectuar el traslado a dependencias policiales, la libre aquiescencia del conductor, en tanto no se regule una norma con rango de ley. Defendemos, por tanto, no otorgar a las fuerzas y cuerpos de seguridad la facultad de doblegar la voluntad de las personas para ser sometidas a una retención policial sin la debida proporcionalidad y congruencia, y solamente por el 
simple motivo de que se les practique una prueba de alcoholemia sin que medie su consentimiento, puesto que, como se ha indicado con anterioridad, esto afecta a la libertad personal de la persona. Es por ello que, ante el vacío legal en todo este asunto, la jurisprudencia se convierte en el mejor valedor, instrumento y medio para señalarnos cómo actuar con todas las garantías de la ley así como, por otra parte, auxiliarnos en la adecuación de los criterios de actuación respecto a esta figura, de modo que, en atención a las circunstancias concurrentes, la actuación más correcta y justa ante una negativa de esta naturaleza, será aquélla que valore las circunstancias concurrentes del caso con el fin de concluir si el hecho se encuentra o no subsumido en un presunto delito contra la seguridad vial para, así, ajustar con proporcionalidad la actuación policial en su deber de perseguir delitos, así como en su misión de garantizar el libre ejercicio de los derechos y libertades de todos y cada uno de los ciudadanos.

\section{BIBLIOGRAFÍA}

Alfonso Pérez, F. (2004), Manual del policía, Madrid, La ley actualidad, $4^{\circ}$ Edición. Asencio Mellado, J. M. (1994), «La detención a los solos efectos de identificación personal prevista en el artículo 20 del proyecto de la Ley Orgánica sobre Protección de la Seguridad Ciudadana», Revista del Instituto Bartolomé de las Casas. Derechos y Libertades, 2, pp. 25-40.

Banacloche Palao, J. (1996), La libertad personal y sus limitaciones, Madrid, MacGraw-Hill.

Bilbao Ubillos, J. M. (2015), «La llamada ley mordaza: Ley Orgánica 4/2015 de Protección de la Seguridad Ciudadana», UNED-Teoría y Realidad Constitucional, 36, pp. 217-260.

Blanco Lozano, C. (2005), Tratado de Derecho Penal Español, Barcelona, Boch Editor, Tomo 2, Volumen 1. [consulta: 26 febrero 2018]. Disponible en: https://2019.vlex.com/\#vid/delitos-libertad-247164.

Casal Hernández, J. M. (1998), Derecho a la libertad personal y diligencias policiales de identificación, Madrid, Centro de estudios políticos y constitucionales.

DuART Albiol, J. J. (2014), Inspecciones, registros e intervenciones corporales en el proceso penal, Barcelona, J.M. Bosch.

Dutú I Guri, M. M. (2013), Los derechos fundamentales: Derecho a la liberad frente a las medidas cautelares penales, Barcelona, Bosch Editor.

FernándeZ-Gallardo Fernández-Gallardo, J. A. (2015), Cuestiones actuales del proceso penal, Barcelona, Experiencia.

Freixes Sanjuan, T. (1993), «Reflexiones sobre la interpretación constitucional del derecho a la libertad personal», Revista Vasca de Administración Pública, 35, pp. 79-104.

García Garcia, C. (2003), Derecho a la intimidad y dignidad en la doctrina del Tribunal Constitucional», Murcia, Servicio de publicaciones de la UMU.

(C) UNED. Revista de Derecho Politico

N. ${ }^{\circ} 111$, mayo-agosto 2021, págs. 191-224 
García Morillo, J. (1995), El derecho a la libertad personal, Valencia, Tirant lo Blanch.

Gimeno Sendra, V. (1988), Constitución y Proceso, Madrid, Tecnos.

Giner Alegría, C. A. (2014), Las medidas cautelares penales personales en el proceso penal español y su vinculación con los Derechos Fundamentales (especial referencia a las recomendaciones internacionales en materia de Derechos Humanos), Nicolás Guardiola J.J. (dir.), Tesis doctoral, Facultad de Ciencias Jurídicas y de la Empresa de la Universidad Católica de Murcia.

Gómara Hernández, J. L., y Agorreta Ruiz, D. (2007), Prontuario de Seguridad Pública e Intervención Policial, Pamplona, Dapp publicaciones jurídicas.

GonzÁlez Montes, F. (2007), «Especialidades procesales en los juicios penales por hechos de tráfico», en MORILLAS CUEVA, L. (coord.), Delincuencia en materia de tráfico y seguridad vial. Madrid, Dykinson, pp. 599-616.

Guillén Álvarez, I. (2015), «Estudio y análisis jurídico de la nueva Ley Orgánica 4/2015, de protección de la seguridad ciudadana», Diario la Ley, 8633.

Jareño Leal, A. (2019), «La privación de libertad a efectos de identificación en la Ley de Seguridad Ciudadana: sus requisitos y la distinción entre delitos e infracciones administrativas de desobediencia y de resistencia en caso de negativa a identificarse, Cuadernos de Política Criminal, 128, Época II, pp. 5-44.

Lombardero Expósito, L. M. (2013), «Conflicto entre derechos fundamentales e investigación policial: el caso del cacheo. Revista Estudios Jurídicos. Segunda Época, 12.

Málaga Diéguez, F. (2001), «Detención y retención», Revista de derecho procesal, 1, pp. 143-170.

MARTín Ríos, P. (2018), «El derecho a la libertad personal frente a la retención policial con fines de identificación», Revista Española de Derecho Constitucional, 12, pp. 87-113.

Matía Portilla, F. J. (1997), El derecho fundamental a la inviolabilidad del domicilio, Madrid, McGraw-Hill.

Montero Rivas J. (2016), Seguridad ciudadana y derechos fundamentales: Luces y sombras de la Ley Orgánica 4/2015, Trabajo fin de Grado inédito, en GUERRERO COLMENARES, M. (dir.), Universidad del País Vasco.

Soto Rodríguez, M. L. (2014), «Las intervenciones corporales y vulneración de derechos fundamentales», Diario la Ley, 8392.

Vidal Prado, C. (1997), «Algunos límites del derecho a la libertad personal: Controles de alcoholemia, legislación y jurisprudencia», Revista de la Facultad de Derecho y Ciencias Políticas, 98, 117-167.

Villaverde MenéndeZ, I., y Cuba Vila, J. (2009), «Alcoholemias, tráfico y otras tribulaciones constitucionales. Punto y aparte en la ley seca de la sanción administrativa», Revista de Documentación Administrativa, 284-285, pp. 181-218. 
Title

Critical analysis of police retention on alcohol screening tests from a constitutional perspective.

\section{Summary}

1. PREVIOUS TERMS: PRESENTATION OF THE ISSUE. 2. POLICE RETENTION AND ITS LIMITATIONS ON THE RIGHT TO FREEDOM IN RELATION TO ALCOHOLIC SCREENING TESTS. 2.1. Background and its legal nature. 2.2. Simple police witholdings. 2.3. Police retention consisting of transferring to police units. 3. INADMISSIBILITY OF THE TERTIUM GENUS IN THE FIELD OF ROAD SAFETY. 3.1. Lack of legal provision. 3.2. Lack of evidences. 3.3. The role played by the acquiescence of the subject for the admissibility of the transfer. 3.4. The principle of proportionality and less distress for third parties. 3.5. The existence of an interest or public demand that justifies the transfer. 4. ADMISSIBILITY IN AN INVESTIGATION EX. ART. 379.2. 5. BY WAY OF CONCLUSION. 6. BIBLIOGRAPHY.

\section{Resumen}

A pesar de que la figura sobre la retención policial no está reconocida como tal en el ordenamiento jurídico procesal español, y, consecuentemente, suscita una evidente polémica en torno a ella por el evidente conflicto de derechos, consideramos que muchas de estas situaciones fácticas - que, sin constituir detención, supongan una privación de libertad-, tienen cabida y, por lo tanto, son legítimas desde una perspectiva constitucional. Sin embargo, en el ámbito de la seguridad vial, suscita aún más controversia, en concreto en aquellas diligencias policiales consistentes en trasladar a dependencias policiales al conductor de un vehículo a fin de practicarle la prueba de detección alcohólica. Para mayor abundamiento a este respecto, hemos de señalar que tampoco existe ninguna norma con rango de ley que contemple esta controvertida figura jurídica que la ampare, al menos, en materia de investigación sobre los delitos contra la seguridad vial. Este conflicto jurídico y de evidentes consecuencias prácticas, no es para nada baladí, en cuanto que este proceder genera actuaciones completamente irregulares o atípicas que pudieren ocasionar actuaciones excesivamente discrecionales. A tenor de la exposición realizada, nos vemos en la obligación de adentrarnos en el estudio de la naturaleza jurídica de la retención policial, que va a consistir en analizar, desde un punto de vista crítico y según el prisma constitucional, aquellos aspectos que legitimen, de algún modo, esta controvertida figura jurídica relacionada con la prueba de detección alcohólica. 


\begin{abstract}
Despite the fact that police retention is not recognized in the Spanish procedural legal system, it brings concern and controversy to the conflict of rights that exist in this space. Considering retention, many of these factual situations — which, without constituting detention, suppose a deprivation of freedom - have a place and represent constitutional perspective. However, when we consider road safety, there is controversy that arises, especially when actions are taken to transfer the driver of a convicted vehicle to a police office location, to complete an alcoholic screening test. Additionally, it is important to recognize that no standard exists which considers this legal figure that has brought much controversy, mostly in crimes related to road safety. These legal conflicts are not trivial, only generating iregular or atypical actions that could cause discretionary actions. In accordance with the presentation made, we are obliged to speak and draw focus to the legal nature of police withholding, with an analysis from a critical point of view, using the constitutional prism which can legitimize the legal figure related to the alcoholic screening test.
\end{abstract}

\title{
Palabras clave
}

Prueba de alcoholemia; delito contra la seguridad vial; retención policial; derecho a la libertad personal; privación de libertad.

\section{Key words}

Alcoholic screening tests; crime against road safety; police withholding; right to personal Liberty; deprivation of freedom. 